\title{
Chapitre VIII \\ Les portraits comme reflets des principaux enjeux du règne
}

Après avoir présenté cette vue d'ensemble des éléments qui s'offrent à l'analyse iconographique, il s'agira dans ce qui suit d'appliquer ces instruments aux tableaux du corpus. Nous allons montrer qu'il est possible de distinguer un certain nombre de sujets et de types de portraits qui se répètent et qui sont repris par des acteurs différents, et qui permettent d'organiser le corpus de tableaux en un nombre assez restreint de groupes d'œuvres similaires ou apparentées. Ces types de portraits peuvent être mis en relation non seulement avec les diverses catégories de commanditaires et destinataires exposées dans la partie précédente, mais aussi avec des situations particulières et des besoins de représentation qui en découlent.

En s’appuyant sur l'héritage de ses pères et en se faisant notamment représenter à côté des couronnes, Marie-Thérèse légitime sa personne et sa nouvelle dynastie. Les Habsbourg-Lorraine ont besoin de réaffirmer leur ancienneté par rapport à leurs territoires comme vis-à-vis des autres dynasties européennes, dont certaines sont plus jeunes et concurrentes comme les Hohenzollern. Les différents royaumes qui composent la Monarchie des Habsbourg-Lorraine sont symbolisés par l'intermédiaire de leurs insignes. Les portraits royaux s'adaptent ainsi aux publics auxquels ils s'adressent. Marie-Thérèse est représentée comme Landesfürstin de ses pays tout comme l'épouse de l'empereur du Saint Empire romain germanique. Pour déchiffrer les discours de légitimation qui se mettent alors en place, les portraits sont analysés sous l'angle des insignes et des symboles représentés. Différents types de portraits deviennent exemplaires par leur nombre et leur contenu. Des modèles de portraits sont repris par les artistes à diverses périodes du règne et sont adaptés à des publics précis : un corps politique relativement stable et permanent s'esquisse ainsi à travers l'image royale.

Si la date de réalisation de certains portraits est connue, il n'est possible d'estimer la période exacte de commande d'un grand grand nombre d'entre eux qu'en nous appuyant sur les insignes représentés dans les portraits (autrement dit sur les types de portraits), et sur la physionomie du corps de Marie-Thérèse. Soulignons toutefois que certains modèles sont reproduits tout au long du règne. L'analyse du contenu des portraits s'articule entre une étude par époque et une étude par public. Certains types de portraits, plus anciens, peuvent être réutilisés des années plus tard, en particulier s’ils mettent en avant les insignes propres aux publics concernés par les tableaux. 
En analysant les couronnes et leur signification, il s'agit de décrire et d'expliquer la symbolique des insignes du pouvoir vis-à-vis de Marie-Thérèse comme des états. Marie-Thérèse est archiduchesse d'Autriche, roi de Hongrie et de Bohême puis impératrice veuve. Pour être plus précise, ses titres sont les suivants à la fin du règne:

Maria Theresia, von Gottes Gnaden römische Kaiserin, Wittib, Königinn zu Hungarn, Böheim, Dalmatien, Croatien, Slavonien, Gallizien, Lodomerien, etc., Erzherzoginn zu Österreich, Herzoginn zu Burgund, zu Steyer, zu Kärnten und zu Krain, Großfürstinn zu Siebenbürgen, Markgräfin zu Mähren, Herzoginn zu Braband, zu Limburg, zu Luxemburg und zu Geldern, zu Würtenberg, zu Ober- und Nieder-Schlesien, zu Mayland, zu Mantua, zu Parma, zu Placenz und Quastalla, Fürstinn zu Schwaben, gefürstete Gräfinn zu Habsburg, zu Flandern, zu Tirol, zu Hennegau, zu Kiburg, zu Görz und Gradisca, Markgräfinn des Heiligen Römischen Reiches zu Burgau, zu Ober- und Nieder Lausitz, Gräfinn zu Namur, Frau auf der Windischen Mark und zu Mecheln etc., verwittibte Herzoginn zu Lotharingen und Baar, Großherzoginn zu Toskana, etc ${ }^{90}$.

Ces nombreux titres représentent les différents territoires sur lesquels MarieThérèse règne.

« La relation entre portrait princier et territoire princier apparaît comme un élément déterminant de la représentation de la Maison des Habsbourg », a pu déclarer Friedrich Polleroß ${ }^{91}$. Les Habsbourg d'Autriche sont très fréquemment peints avec les symboles de leur pouvoir, en premier lieu avec les couronnes qui sont représentées à leurs côtés ou sur leur tête. À travers ces insignes, les portraits montrent les souverains aussi bien dans leur fonction d'empereur que de roi et de seigneur féodal. La répétition des mêmes types de portraits agit à la manière d'un exemplum, d'un exemple distribué à tous par l'intermédiaire de nombreuses copies et répliques, ce qui permet ainsi une certaine forme de légitimation.

Les multiples titres de majesté des Habsbourg leur permettent de changer d'apparence et de s'adapter aux publics comme aux évènements. Ces changements et ces évolutions commencent lors des cérémonies de couronnement des Habsbourg dans leurs différents pays, avant de se traduire dans leur iconogra-

90 Gall, Österreichische Wappenkunde, p. 50.

91 Polleross, "Kaiser, König, Landesfürst », p. 189. Friedrich Polleroß distingue principalement deux grandes périodes pour ce type de représentation montrant les souverains avec les couronnes de leurs États. La première période commence au XV $\mathrm{X}^{\mathrm{e}}$ siècle avec Frédéric III, la seconde correspond globalement à l'avènement de Charles VI et perdure tout au long du XVIII ${ }^{\mathrm{e}}$ siècle, pp. 189-193. Comme le rappelle Polleroß, toute la complexité de la situation politique et juridique des Habsbourg, les rapports qu'ils entretiennent avec leurs territoires, sont illustrés non seulement dans les portraits d’État mais aussi dans les cérémoniels étatiques lors des cérémonies d'hommage et de couronnement. 
phie. Outre le cérémonial et la présentation des insignes, la réception du vêtement de couronnement, avec lequel les souverains sont vêtus et représentés dans les portraits, est un autre élément important ${ }^{92}$. Dans les différents tableaux, Marie-Thérèse change également de vêtements au gré des différents types de représentation, certains habits comme la robe du couronnement hongrois reviennent plus souvent que d'autres.

\section{Une souveraine qui suit les rites et les traditions des pays}

La mise en évidence des insignes régionaux est frappante. Marie-Thérèse s'adresse à ses pays par l'entremise des couronnes et réciproquement, les pays voient et mettent en scène eux-mêmes leur souveraine avec des habits et insignes nationaux.

Marie-Thérèse doit affronter au début de son règne l'une des crises les plus graves de l'histoire de la Monarchie, alors sur le point de se désagréger, qui nécessite la mise en œuvre rapide d'une politique de légitimation par tous les médias, y compris l'iconographie. Les portraits reflètent à leur manière des enjeux conjoncturels, politiques et diplomatiques qui s'articulent autour de certains évènements importants du règne de Marie-Thérèse comme les guerres de Succession d'Autriche et la guerre de Sept Ans, la perte définitive de la Silésie, et celle provisoire de la couronne impériale entre 1742 et 1745.

Dans son Testament Politique de 1750-1751, Marie-Thérèse évoque les rivalités qui, jusqu'au gouvernement de son père, opposaient les Autrichiens, les Hongrois et les Tchèques à la cour ${ }^{93}$. Selon elle, l'ensemble des ministres aurait davantage été composé d'Autrichiens que de personnages issus de Bohême, sans parler des Hongrois, très minoritaires, et ces derniers auraient toujours nourri le sentiment d'être tenus constamment à l'écart, leur nation étant exclue de tous les services ${ }^{94}$. Marie-Thérèse, à ses propres dires, tente de remédier à cette injustice faite aux Hongrois. Leur fidélité du début du règne est récompensée par la souveraine et devient même la base de son régime. Marie-Thérèse

92 La cérémonie au cours de laquelle le souverain change de vêtements, qui existe déjà dans la Rome ancienne, acquiert une nouvelle signification au Moyen-Âge qui perdure à l'époque moderne ; Vácha, " 'Mutatio vestis' », pp. 252-253. Sur l'importance du sacre royal, voir plus généralement Cornette, Le roi de guerre, pp. 213-215 ; Cornette, « La puissance des objets »; Milovanovic, « Cérémonies et symboles », pp. 144-147.

93 Kallbrunner, Politische Testamente; voir aussi Klingenstein, « Was bedeuten ‘Österreich' und 'österreichisch' », p. 166.

94 Walter, Maria Theresia, p. 77. 
s'efforce de réunir tous ses pays autour de sa personne comme en témoigne sa représentation aux côtés des couronnes de Hongrie, de Bohême et d'Autriche. Ses portraits proposent une succession d'images et les couronnes, peintes selon un ordre bien précis, reflètent des revendications exprimées ou déjà exaucées.

Les portraits de Marie-Thérèse peuvent être analysés comme des discours construits tant par les spectateurs que par les émetteurs. Il est possible de se demander s'il s'agit d'un discours de contrat ou de conquête, pour reprendre la dialectique chère à Luc Duerloo ${ }^{95}$. Dans le cas de Marie-Thérèse, il faudrait davantage parler d'une conquête qui passe par la voie du contrat. L'intégration, implicitement consentie et même revendiquée par les élites elles-mêmes, se traduit par la commande ou l'exposition des mêmes types de portraits de MarieThérèse. Les grands s'approprient cette image. Si Marie-Thérèse assure et confirme son autorité lors de l'accession au trône par l'envoi ou la commande de tableaux, réciproquement, les états et les nobles assurent leur position en exposant un portrait de Marie-Thérèse représentée à côté de leurs insignes respectifs. Les grands serviteurs de l'État et leurs familles sont tous liés entre eux. Nous pouvons avancer l'idée d'une construction autour de conceptions de la Monarchie et surtout de sa souveraine. Les conceptions et les représentations de la Monarchie se construisent dans un dialogue entre le pouvoir Habsbourg et de nombreux autres acteurs. Ce dialogue révèle des éléments partagés sur lesquels bâtir cet organisme politique avec ses représentations iconographiques. Les différentes dynamiques s'engagent dans une même voie autour de la figure royale et dynastique.

Les portraits, en particulier les copies et les répliques des modèles officiels, sont très demandés à différentes époques du règne par des commanditaires impériaux, ecclésiastiques, urbains ou nobiliaires. En se fondant sur l'analyse des types de portraits, on constate au fil des années une véritable banalisation et popularisation de certains modèles, parmi lesquels les plus facilement identifiables sont ceux de Marie-Thérèse en roi de Hongrie ou son portrait équestre lors de la cérémonie du couronnement hongrois. Toutefois, au début du règne, l'image d'une jeune archiduchesse est déjà tout particulièrement diffusée.

95 Duerloo, « Discourse of Conquest ». 


\section{Les portraits et les phases de la légitimation: les portraits et les pays de la Monarchie}

\section{a. L'image d'une archiduchesse}

La représentation de Marie-Thérèse commence dès son enfance. Les premiers portraits, comme celui réalisé par Andreas Möller en 1729, présentent l'image d'une jeune princesse particulièrement belle et gracieuse. Après 1740, au moment de l'avènement de Marie-Thérèse au pouvoir, le peintre officiel Martin van Meytens met en évidence le chapeau archiducal aux côtés de la souveraine.

Le portrait qu'Andreas Möller exécute en 1727 (P 1, Figure 1), alors que Marie-Thérèse a dix ans, représente une jeune archiduchesse d'Autriche, belle et féminine. Cette mise en scène de Marie-Thérèse durant les premières années de sa vie correspond à une représentation typiquement féminine des princesses de l'époque ${ }^{96}$. Ce portrait est l'une des trois toiles que Charles VI commande auprès du Danois Möller et du peintre Hongrois Adam Manyoki pour représenter ses filles, les archiduchesses Marie-Thérèse, Marie-Anne et Marie-Amélie. Elles sont peintes toutes les trois de manière similaire ${ }^{97}$. Le portrait de Möller propose l'image quelque peu idéalisée d'une jeune fille d'un peu plus de dix ans. Les fleurs dominent différentes parties de la composition. De sa main droite, Marie-Thérèse saisit l'une d'entre elles de manière gracieuse.

Les portraits des premières années de la vie de Marie-Thérèse la représentent comme une jeune archiduchesse autrichienne qu'on peut considérer comme séduisante $^{98}$. Charles VI pense encore à la marier à l'étranger, espérant encore avoir un fils.

À ce type de portraits de jeunesse avant l'arrivée au pouvoir succèdent les portraits représentant Marie-Thérèse dans son rôle d'archiduchesse d'Autriche, de Landesfürstin. Analysons ainsi trois versions d'un même type de portrait, commandées à trois périodes du règne, en 1740, 1744 et 1759, par des comman-

96 Il existe aussi d'autres portraits de Marie-Thérèse encore jeune archiduchesse. Au moins deux ont été réalisés par Meytens, dont l'un se trouve au château de Gripsholm en Suède, l'autre dans la collection Strakovits à Budapest ; voir Banakas, « Maria Theresia als junge Erzherzogin »; Lisholm, Martin van Meytens, p. 99.

97 Voir notes 133, 134 et 135, chapitre II.

98 Stollberg-Rilinger, Maria Theresia, p. 249: « Die Schönheit der Königin war deshalb eine mächtige politische Legitimationsquelle und wurde umso mehr beschworen, als es galt, Maria Theresias prekäres Erbrecht zu verteidigen ». Concernant la beauté de la souveraine en ses jeunes années, voir aussi un dessin de Gabriel Mathei, vers 1740, voir Englebert, Charles Joseph Fürst de Ligne, pp. 40-41. Voir aussi les portraits de jeunesse P 1, P 3, P 4. 
ditaires, issus d'ordres divers, mais provenant tous des pays héréditaires autrichiens. Ces tableaux ont pour point commun de représenter la souveraine à côté de trois couronnes, le chapeau archiducal étant disposé devant les couronnes de Hongrie et de Bohême. Il s'agit donc nettement de portraits de MarieThérèse en archiduchesse d'Autriche.

Le plus ancien des trois tableaux est exposé dans la Galerie Slovène de Ljubljana (P 6, Figure 25), la seconde version se trouve dans le Musée de la ville de Vienne (P 12), tandis que le troisième est resté dans son lieu d'origine, l'abbaye de Melk en Autriche (P 13). Ils correspondent à trois périodes de la représentation de Marie-Thérèse. Au moment de leur réalisation, ces tableaux concernent différents types de public : nobiliaire, urbain, ecclésiastique. La même iconographie avec le chapeau archiducal au premier plan a été réutilisée à chaque fois, reflétant l'intérêt porté à une fonction donnée : Marie-Thérèse comme archiduchesse d'Autriche. Le portrait s'adapte aussi à un public précis et peut servir à souligner une origine commune, comme ici l'appartenance des destinataires aux pays héréditaires autrichiens.

Le premier portrait est réalisé par Martin van Meytens. Exposé aujourd'hui dans la Galerie nationale de la capitale slovène, à Ljubljana, ancienne Laibach, qui faisait alors partie du duché de Carniole, il se trouvait à l'origine dans la villa de Leopoldsruhe (aujourd'hui Cekínov Grad) appartenant au comte Léopold Lamberg, famille très proche de Marie-Thérèse ${ }^{99}$. Le second portrait, également de Meytens, est une réplique exacte du précédent, surmontée d'un médaillon de l'archiduc Joseph enfant placé au-dessus du tableau. Le tableau de MarieThérèse et de son fils est marqué de la rare inscription "Martin de Meytens pinxit ». Aujourd'hui conservé au Musée historique de la ville de Vienne, ce portrait était suspendu au XVIII ${ }^{\mathrm{e}}$ siècle avec d'autres portraits d'empereurs dans la Kaisersaal de l'ancien hôtel de ville de la capitale. La disposition du chapeau archiducal devant les autres couronnes pourrait suggérer que la version originale de Carniole est réalisée avant le couronnement hongrois de 1741, la présence des couronnes de Hongrie et de Bohême, légèrement en retrait du chapeau archiducal, pourrait alors être interprétée comme un signe de revendication sur les couronnes de Hongrie et de Bohême. Le portrait de l'hôtel de ville de Vienne présente exactement la même répartition des couronnes mais est commandé

99 Zeri, Rozman, European Paintings, pp. 176-177, p. 176. Dans cet ouvrage, il est dit qu'une réplique de ce portrait se trouve au Musée historique de la ville de Vienne. Le portrait viennois est mentionné comme une réplique de ce tableau slovène. L'auteur rajoute même que le portrait de Vienne pourrait avoir été réalisé par l'atelier de Meytens en raison des détails simplifiés. Weiss, Festschrift aus Anlaß der Vollendung, pp. 19-20. 
en 1744 auprès de Meytens par la ville de Vienne ${ }^{100}$. C'est la raison pour laquelle la représentation de Joseph, probablement âgé de trois ans, est rajoutée en médaillon au-dessus du portrait de sa mère.

Réalisé plus tard en 1759, le troisième portrait se trouve dans la galerie des souverains autrichiens du couvent de Melk. Le peintre Joseph Kremer entreprend cette galerie et réalise les portraits des Babenberg et des Habsbourg jusqu'à Charles VI et sa fille Marie-Thérèse ${ }^{101}$. Au sein de l'abbaye de Melk, la commande témoigne de fidélité vis-à-vis de la dynastie, de la souveraine et de l'Autriche ${ }^{102}$. C'est la représentation la plus classique qui soit de fidélité à une dynastie : la galerie complète de ses souverains successifs. La mise en valeur de l'archiduché d'Autriche est ici l'élément central, comme l'illustre le fait que le chapeau archiducal soit le seul insigne représenté. La relation particulière entre l'abbaye et la dynastie est ainsi soulignée. Le portrait est un pendant à ceux du début de la série qui font allusion à la position de résidence margraviale que Melk avait occupée sous les premiers Babenberg. Le peintre s'adapte dans ce cas aux intérêts du commanditaire et représente Marie-Thérèse dans son rôle d'archiduchesse autrichienne. La comparaison de ces trois reprises d'un même type de portrait illustre bien comment, au cours du règne, un répertoire d'images, s'offre aux artistes. Avec les commanditaires, au gré de leurs besoins et de leurs souhaits, ces artistes élaborent différents portraits.

Si des élites autrichiennes commandent ce motif tout au long du règne afin de mettre en valeur les insignes autrichiens, au début des années 1740 ils ne sont pas les seuls. Ainsi en 1740, l'archévêque de Kalocsa, Gabriel II Herman de Patarcic, dans l'attente de la visite royale, commande un portrait de MarieThérèse, probablement auprès de Johann Gottfried Auerbach (P 14) ${ }^{103}$. Ce tableau, lui aussi, la représente à côté du seul chapeau archiducal.

À partir des écrits de la souveraine, notamment de son Testament Politique, nous pouvons trouver des éléments d'explication concernant sa situation et sa position vis-à-vis de ses états. Il est essentiel de prendre en compte le point de vue de Marie-Thérèse sur ses territoires. Son analyse de la situation, très grave dans l'histoire de la Monarchie, à laquelle elle doit faire face, est intéressante $^{104}$. Inexpérimentée, jeune, sans aide, abandonnée par des ministres désorientés, attaquée de toutes parts, c'est ainsi que Marie-Thérèse présente sa situation dans ses mémoires. Cette image d'une Monarchie sur le déclin et

100 Voir note 375, chapitre V.

101 Merci à l'abbaye de Melk et à Maria Prüller pour les informations concernant Kremer.

102 Renvoyons sur ce point au chapitre V.

103 Buzási, «Auerbach ».

104 Kallbrunner, Kaiserin Maria Theresias Politisches Testament, pp. 25-73. 


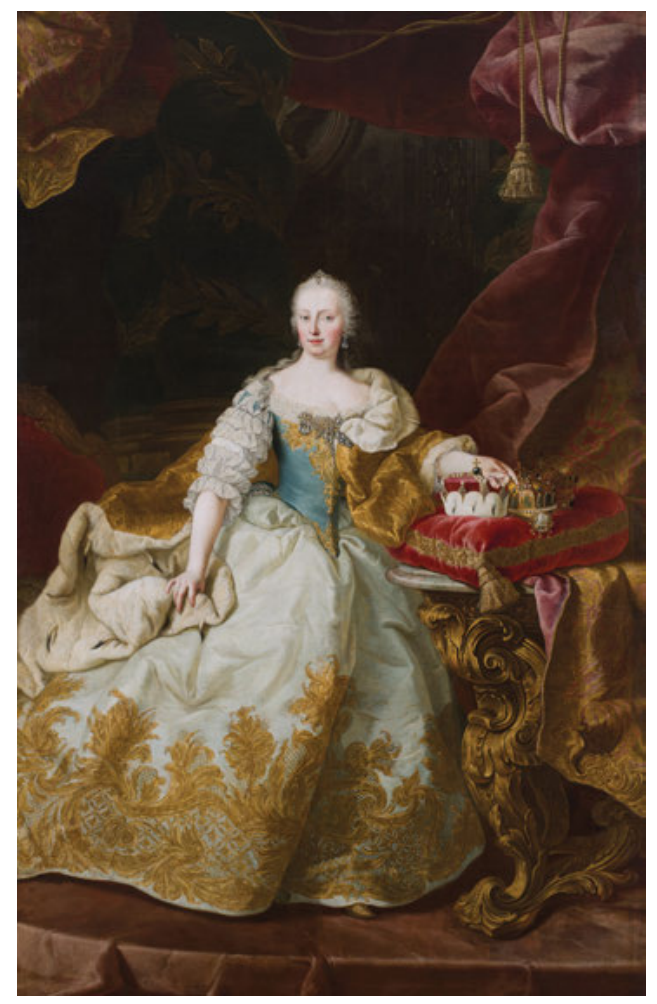

Figure 25: Martin van Meytens le jeune, Marie-Thérèse, vers 1740-1742, 280 x 184,5 cm, Inv. No. NG S 1350, photo de Bojan Salaj, Galerie Nationale de Slovénie, Ljubljana, Slovénie, (C) Narodna Galerija, Ljubljana.

d'une jeune reine seule est également corroborée par des contemporains de la souveraine ${ }^{105}$. Dans ce contexte, la représentation et la diffusion d'images spécifiques de la souveraine s'avère particulièrement nécessaire. Tant que MarieThérèse n'est pas couronnée roi de Hongrie et de Bohême, elle ne peut être représentée avec les couronnes de ces pays qu'à titre de revendication, ce qui est le cas dans le portrait de Ljubljana qui vient d'être évoqué. Meytens et ses collaborateurs ont en effet peint la main de la souveraine reposant sur le chapeau archiducal mais tendue en direction de la couronne de Hongrie, semblant montrer la direction à prendre. Le couronnement hongrois est la prochaine étape.

105 Voir les mémoires du comte Nény, Mémoires historiques et politiques sur les Pays Bas autrichiens, pp. 190-192. 


\section{b. La représentation en roi de Hongrie : une image répandue}

Après les cérémonies d'hommage autrichien effectuées en 1740, il est primordial pour Marie-Thérèse de se faire couronner roi de Hongrie et de Bohême. Premier des outils symboliques du pouvoir, le sacre royal est un rituel particulièrement important, si ce n'est fondamental, qui fonde et confirme l'autorité souveraine ${ }^{106}$. Le sacre authentifie et légitime la force et la légitimité des souverains car la succession royale et l'hérédité ne suffisent pas. L'exemple de Marie-Thérèse est particulièrement éloquent à cet égard. Après cette cérémonie, le souverain est pleinement et totalement roi, même si dans le cadre de la Monarchie autrichienne, elle n'a pas une signification aussi sacrée qu'en France ${ }^{107}$.

De nombreux portraits du corpus représentent Marie-Thérèse en roi de Hongrie, vêtue des habits de couronnement et proche de la couronne de Saint Étienne. Si l'on comptabilise d'autres types de portraits où la couronne de Hongrie est mise en valeur par rapport aux autres couronnes, ou qui montrent d'autres symboles hongrois comme l'habit traditionnel ou l'Ordre de Saint-Étienne, on compte largement plus de la moitié des tableaux du corpus qui font référence à la Hongrie.

Ces relations renforcées entre Marie-Thérèse et la Hongrie débutent dès la diète hongroise de 1741, qui correspond à un moment crucial pour MarieThérèse, car ce couronnement doit confirmer la légalité et la validité de la Pragmatique Sanction. Pour sceller l'accord entre la jeune souveraine et la Hongrie, le couronnement de Marie-Thérèse en tant que " roi » est indispensable. Celleci ne peut être reconnue comme souveraine légitime tant que la couronne de Saint Étienne, garantie de légitimité pour elle et assurance de leurs libertés pour les nobles hongrois, n’a pas été posée sur sa tête.

La cour attend en outre l'octroi d'un soutien militaire de la part des états hongrois. Un peu avant son couronnement en tant que roi de Hongrie, le 21 juin 1741, Marie-Thérèse explique clairement dans une lettre destinée aux états que leurs subsides sont indispensables. Au cours de son allocution à la diète de 1741, l'ami et conseiller de Marie-Thérèse, le comte Grassalkovich, évoque la concorde et l'union, comme l'unique moyen de favoriser l'intérêt général et le service dans le royaume ${ }^{108}$. Plus tard, lors de la journée du Vitam et Sanguinem le 11 septembre 1741, au cours de laquelle la jeune souveraine avait fait appel au soutien des Hongrois, Marie-Thérèse et les pays apparaissent unis contre les prétentions de

106 Cornette, Le roi de Guerre, p. 213.

107 Milovanovic, « Cérémonies et symboles », pp. 144-147.

108 Barcsay, Herrschaftsantritt, p. 222. 
Charles Albert de Bavière. C'est aussi une alliance contre Frédéric II de Prusse. Marie-Thérèse, déjà couronnée depuis juin, revient à Presbourg demander de l'aide aux Hongrois qui jurent de l'aider et de donner leur vie et leur sang pour leur reine. Au début du règne s'établit donc un consensus autour des intérêts bien compris de chacun qui se rejoignent provisoirement. Les états s'entendent pour protéger le droit héréditaire de la souveraine tandis que Marie-Thérèse se présente comme la garante et la protectrice des lois du royaume ${ }^{109}$.

\section{La Sainte Couronne de Hongrie comme incarnation du royaume de Hongrie}

Une très ancienne tradition attribue la sainte couronne au premier roi de Hongrie, Saint Étienne, figure emblématique du royaume. Fondateur de l'État hongrois, celui-ci se convertit au christianisme en 976. La couronne est conservée suivant des lois très strictes dès le $\mathrm{XV}^{\mathrm{e}}$ siècle, la première description de la couronne remonte au début du XVII ${ }^{\mathrm{e}}$ siècle ${ }^{110}$. La couronne hongroise est formée de deux parties, la corona latina et la corona graeca. Couverte d'émaux, elle est surplombée d'une croix inclinée, deux cercles se croisent au-dessus d'un troisième, décoré de plaques d'or émaillées.

Le roi Étienne et sa femme Gisèle obtinrent en effet, selon la tradition, en l'an 1000, la couronne royale de Hongrie des mains du pape en personne ${ }^{111}$. Cette origine plus ou moins mythique confère une importance presque sacrale à la couronne de Saint Étienne rehaussant de fait le rang du monarque couronné avec cet attribut. Considérée comme sacrée, elle est très souvent désignée dans les documents dès le XIII ${ }^{\mathrm{e}}$ siècle comme sacra, sancta ou même sacra, sanctissima corona ${ }^{112}$, couronne sainte ou sacrée, d'où l'importance de cette couronne dans les portraits de Marie-Thérèse, en raison notamment de la séparation entre l'empereur et le souverain des territoires héréditaires. Tant qu'il n'est pas couronné légalement, avec les insignes traditionnels du pouvoir et après l'approba-

109 Barcsay, Herrschaftsantritt, p. 269.

110 Révay, De Sacrae Coronae Regni Hungariae ortu ; voir là-dessus Lovag, "L'intégration de la couronne latine et de la couronne grecque », pp. 62-71.

111 Kelleher, The Holy Crown of Hungary, p. 2.

112 Kelleher, The Holy Crown of Hungary, p. 2. Dès la fin du XVIII ${ }^{\mathrm{e}}$ siècle, les premiers ouvrages érudits qui proposent la reproduction exacte et la description précise de la couronne sont publiés ; voir notamment Katona, Dissertatio critica ; Koller, De Sacra Regni Ungariae Corona commentarius. Ces livres peuvent voir le jour grâce à l'exposition au public de la couronne lors de son retour de Vienne après la mort de Joseph II. Ce dernier n’a jamais été couronné pour ne pas devoir renégocier avec les états et de fait reconnaître leurs privilèges et leur autonomie par rapport au pouvoir central. Voir Lovag, "L'intégration de la couronne latine et de la couronne grecque », pp. 62-71; Bodnár, « La Sainte Couronne de Hongrie », pp. 3-82. 
tion des états, la position du roi n'est pas supérieure à celle d'un autre magnat dans le royaume ${ }^{113}$. Seul le souverain couronné avec la Sainte Couronne est reconnu comme légitime, ceci est un point essentiel ${ }^{114}$.

Sous les rois de la Maison des Árpád, l'utilisation de la couronne, du sceptre et du globe royal est devenue coutumière, ajoutée à une chape liée à la personne de Saint Étienne ${ }^{115}$. Probablement depuis la fin du XII ${ }^{\mathrm{e}}$ siècle, et jusqu'en 1916, date à laquelle a lieu le couronnement du dernier roi de Hongrie Charles IV, époux de l'impératrice Zita, tous les rois hongrois sont couronnés avec la Sainte Couronne ${ }^{116}$. Suivant la tradition, la Sainte Couronne de Hongrie appartient aux états, elle est même l'incarnation de l'État hongrois, c'est elle qui fait l'État et le roi. En se faisant si souvent représenter avec la couronne de Saint Étienne sur laquelle elle pose même parfois la main d'un geste protecteur, Marie-Thérèse revendique une propriété, ou du moins une copropriété, sur la Sainte Couronne de Hongrie. La double croix également représentée dans les portraits symbolise, quant à elle, les armoiries hongroises et la capacité des rois de Hongrie à désigner et nommer les archevêques.

L'étape du couronnement est d'autant plus décisive qu'en 1741, les Hongrois apparaissent comme les premiers et principaux soutiens de Marie-Thérèse et de la Monarchie. La représentation de Marie-Thérèse comme roi de Hongrie peut ainsi être interprétée comme la représentation de la force et de l'indépendance des Hongrois et comme une façon pour Vienne de s'attirer leurs faveurs.

Les différentes postures et les types de représentation de Marie-Thérèse reflètent divers arguments de légitimation. Marie-Thérèse est représentée dans plusieurs portraits avec la couronne de Hongrie sur la tête. Cette image est à

113 Kelleher, The Holy Crown of Hungary, pp. 3-5. Comme l'évoque Patrick Kelleher, le décret du roi Matthias Corvin constitue l'une des premières mesures de sauvegarde. On déclare en 1464 que la couronne doit être protégée. C'est même une question d'intérêt public. Dès le début $\mathrm{du} \mathrm{XVI}{ }^{\mathrm{e}}$ siècle, la diète hongroise désigne deux gardiens permanents de la couronne chargés d'assurer sa protection. Lors de l'extinction de la maison régnante des Árpád en 1301, la Sainte Couronne est un enjeu pour les partis en guerre. C'est un instrument d'autorité. Par la suite, l'époque de domination ottomane de la Hongrie entraîne pour la couronne des changements fréquents de résidences. Il s'agit de la placer en sûreté loin de tout danger durant les $\mathrm{XVI}^{\mathrm{e}}$ et XVII ${ }^{\mathrm{e}}$ siècles.

114 Bárány-Oberschall, Die Sankt Stephans-Krone, pp. 7-14; Kelleher, The Holy Crown of Hungary, pp. 1-4.

115 Tóth, "The Holy crown and coronation insignia », pp. 37-40 ou du même auteur, la version française, « La Sainte Couronne du royaume hongrois », pp. 26-28.

116 Bárány-Oberschall, Die Sankt Stephans-Krone, pp. 14-18; Deér, Die Heilige Krone Ungarns, voir notamment l'introduction, pp. 11-31; Kovács, Lovag, The Hungarian Holy Crown and the Coronation Regalia; Tóth, Szelényi, The Holy Crown of Hungary, Kings and Coronations. 
mettre en relation avec le rituel et la cérémonie du couronnement hongrois. Marie-Thérèse est en 1741 bel et bien couronnée comme « roi »de Hongrie, rex foemina, pour être plus précis ${ }^{117}$. Au cours de la cérémonie, la souveraine reçoit la couronne sur la tête. Cette distinction confère à Marie-Thérèse le rang de véritable souverain, et non de femme du roi. Les épouses des rois de Hongrie ne portent pas la couronne de Saint Etienne sur la tête, elle est posée sur leur épaule droite ${ }^{118}$. Lors du couronnement, le sceptre est remis dans la main droite de Marie-Thérèse et l'orbe dans la main gauche. Le prince archevêque Imre Esterházy et le palatin Pálffy posent ensemble la couronne sur la tête de la souveraine tandis que les personnes présentes dans l'église crient Vivat Domina et Rex Noster ${ }^{119}$.

Marie-Thérèse n'est pas l'épouse d'un roi comme les autres femmes de sa dynastie, et elle et son entourage viennois ont insisté qu'elle soit couronnée " non comme une épouse de roi mais comme un roi lui-même ", " nit als eine Gemahlin eines Königs, sondern wie ein König selbsten gekrönet werden » ${ }^{120}$. Lors de la session de la diète du 29 juin 1741, le primat de Hongrie plaide pour l'utilisation de la formule Vivat Domina et Rex Noster qui contient une formulation masculine, " notre roi ${ }^{121}$. Plus d'une dizaine de portraits du corpus représentent Marie-Thérèse avec la couronne posée sur la tête. Ils se trouvent principalement en Hongrie mais aussi dans d'autres provinces de la Monarchie, commandés tout au long du règne par divers commanditaires qui ne sont pas seulement hongrois. Les souverains commémorent le couronnement et leur légitimité nouvellement acquise en portant la couronne sur leur tête, façon de témoigner de leur droit à en disposer.

La fréquence des portraits avec la couronne de Saint Étienne peut aussi faire allusion à l'accès physique à cet objet sacré, toujours possédé et jalousement gardé par les états du royaume de Hongrie, même si le droit de la dynastie à en disposer a progressé. En effet, dès le couronnement de Joseph $\mathrm{I}^{\mathrm{er}}$ en $1687^{122}$, les états hongrois reconnaissent définitivement la succession héréditaire des Habsbourg.

117 Voir Serfőző, «'Männlich' und mächtig », p. 107.

118 Bárány-Oberschall, Die Sankt Stephans-Krone, p. 18. La distinction est maintenue jusqu'au banquet après le couronnement, où le roi arrive la couronne sur la tête, tandis que lors des couronnements de reines, le devoir de transporter la couronne revient au palatin; voir Pálffy, « Krönungsmähler in Ungarn », vol. 116, pp. 76-77.

119 Holčík, Korunovačné slávnosti, p. 37.

120 Barcsay, Herrschaftsantritt, p. 206.

121 Barcsay, Herrschaftsantritt, pp. 206-207.

122 Sur la dimension symbolique de cet évènement, voir Smíšek, « Uherská korunovace ». 
Puisque les états possèdent les couronnes, la représentation de MarieThérèse couronnée acquiert un sens supplémentaire, comme une manière d'illustrer l'unité entre la souveraine et ses couronnes, en signe d'appropriation royale. De même, lorsqu'ils commandent des portraits de Marie-Thérèse à côté de la couronne de Hongrie et en habits hongrois, certaines élites hongroises s'approprient la figure de leur souveraine en la représentant comme une des leurs.

Les représentations du couronnement, ou des parties de la cérémonie, sont courantes chez les Habsbourg depuis au moins 1563, comme nous certifie Friedrich Polleroß ${ }^{123}$. L'intérêt stratégique d'une telle représentation est bien compris par les deux partis, impérial et hongrois. Il s'agit de se créer des souvenirs communs d'un côté comme de l'autre, en établissant des preuves de possession de la couronne de Saint Étienne pour la cour, et des témoignages d'une forme de proximité avec le pouvoir royal de la part des Hongrois. Les portraits de Marie-Thérèse avec la couronne de Hongrie sont en soi les modèles d'une relation exemplaire.

L'apogée de ce rapprochement entre le roi et la Nation des nobles a lieu lors de l'apparition de Marie-Thérèse à la diète du 11 septembre 1741. La souveraine déclare à ses états qu'elle souhaite dès à présent séjourner au milieu de son royaume, in medio regni ${ }^{124}$. On peut considérer que dans les portraits où elle entourée de la couronne de Saint Étienne et des autres insignes royaux, vêtue des habits du couronnement, cette promesse est réalisée au niveau symbolique. Le système de signes traditionnels du royaume de Hongrie intègre en effet le souverain dans la nation ${ }^{125}$.

Les habits de couronnement renvoient aussi bien à la tradition hongroise qu'à une marque de sympathie de la part de Marie-Thérèse, comme des Habsbourg plus généralement, vis-à-vis des symboles de cette nation. Comme nous renseigne Katalin Földi-Dózsa : « Elle essayait ainsi à chaque occasion d'utiliser ce costume pour se gagner les Hongrois. De manière ostentatoire, elle portait sans cesse cet habit et faisait ainsi vêtir ses enfants. C'est de cette manière qu'elle rendit l'habit hongrois populaire à la cour viennoise ${ }^{126}$.

L'historien d'art Friedrich Polleroß s'est également penché sur la question. Selon ses estimations, si l'empereur Charles VI est parfois montré en roi de Hongrie en miniature et dans des gravures imprimées, ce type de représentation augmente considérablement avec l'arrivée au pouvoir de Marie-Thérèse.

123 Polleross, « Austriacus Hungariae Rex », pp. 72-74.

124 Barcsay, Herrschaftsantritt, p. 270.

125 Barcsay, Herrschaftsantritt, pp. 268-271.

126 Földi-Dózsa, « Die ungarische Nationaltracht », p. 25. 
Entre 1740 et 1743, la dignité royale hongroise est le rang le plus important de la maison d'Autriche ${ }^{127}$. Vêtue à la manière hongroise dans les portraits commémorant le couronnement de Presbourg, Marie-Thérèse se situe dans une tradition familiale ainsi que dans la continuité d'une tradition hongroise noble. Dès la seconde moitié du XVI ${ }^{\mathrm{e}}$ siècle, les nobles hongrois eux-mêmes, et non seulement les monarques, aiment à se faire représenter en costume hongrois. À la fin du siècle, c'est au tour des femmes de se laisser représenter en portrait de cette manière. Dans les pays, au sein de la nation hongroise elle-même, les éléments dits nationaux sont mis en valeur : " Le monarque hongrois, bien qu'il fût un archiduc de la Maison de Habsbourg, devait tôt ou tard marquer son rang royal au moyen de ses habits ${ }^{128}$.

Marie-Thérèse porte l'habit national afin de se gagner la faveur des Hongrois, principalement au moment du couronnement hongrois, qui donne lieu à de belles représentations de la souveraine en roi de Hongrie, mais aussi plus tard. Son fils et héritier, l'archiduc Joseph est de même très souvent peint en habit de Hussard hongrois comme d'autres enfants nobles de l'époque. Il s'agit de rappeler que le petit Joseph est destiné à devenir un jour roi de Hongrie, successeur de Marie-Thérèse ${ }^{129}$.

Par son couronnement en tant que roi de Hongrie, Marie-Thérèse s'inscrit volontairement et de fait comme héritière, dans la lignée des rois de Hongrie depuis Saint Étienne. En exerçant tout au long de son règne une forme de mécénat en faveur des insignes nationaux ${ }^{130}$, Marie-Thérèse apparaît, et surtout se représente, comme un soutien capital des traditions hongroises. Elle fonde ainsi l'Ordre de Saint-Étienne en 1764 sur lequel nous reviendrons dans le dernier chapitre.

\section{Les portraits de Marie-Thérèse ou la visualisation du rapport entre le royaume de Hongrie et la Monarchie : un portrait exemplaire présent partout}

La loi de la Pragmatique Sanction de 1713, acceptée en 1722-1723 par la diète hongroise, stipule que les royaumes sont unis de manière inséparables et indivisibles ${ }^{131}$.

127 Polleross, « Austriacus Hungariae Rex », p. 67.

128 Földi-Dózsa, « Die ungarische Nationaltracht », p. 23.

129 Martin van Meytens, Joseph II en habit hongrois vers 1745, huile sur toile, 140 x $110 \mathrm{~cm}$, KHM Gemäldegalerie, Vienne, Inv. Nr. 7059. Martin Johann Schmidt, Marie-Thérèse et Joseph II, 1745, huile sur toile, 229 x $157 \mathrm{~cm}$, Stift Seitenstetten. Martin van Meytens, Joseph à l'âge de six ans, 1747, huile sur toile, 150 x 112 cm, Národní Galerie, Prague, Inv. Nr. 0787 ; cités par FöldiDózsa, « Die ungarische Nationaltracht », p. 28.

130 Galavics, « Ahnen, Helden, Heilige», p. 778.

131 Csáky, « Die Einordnung Ungarns », pp. 156-158 ; Fazekas, Ujváry, « Katalog », pp. 150-151 ; Gergely, « Staatsrechtliche Beziehung », p. 29 ; Ingrao, « Die Transformation der ös- 
En reconnaissant la Pragmatique Sanction, les états hongrois acceptent, de fait, de vivre avec les autres pays de la Monarchie. Si la libre élection du roi de Hongrie a certes été supprimée en 1687, la Nation (la noblesse) obtient toujours le Geleitsbrief, lettre de sauvegarde, de maintien de leurs droits, lors de l'arrivée d'un nouveau souverain sur le trône $e^{132}$. Le nouveau roi prête serment de respecter les droits et libertés des états. Cette missive est formulée et rédigée avec eux. Sans cette lettre, il n'est pas possible de mettre au point un diplôme inaugural ni même le couronnement. Sans couronnement avec la Sainte Couronne, les droits du roi ne peuvent pas être exercés ${ }^{133}$.

« La coopération entre la cour et les états ne pouvait avoir lieu sans accrocs. Dans l'histoire du XVIII ${ }^{\mathrm{e}}$ siècle, il n'y eut pas une diète hongroise qui ne commençât pas par une dispute entre le souverain et les états » a pu écrire Janós Barta ${ }^{134}$. Pour éviter ces conflits récurrents, notamment au sujet des impôts, la cour décide à plusieurs reprises de suspendre la diète. Bien que sa convocation soit en principe fixée tous les trois ans par la loi, les intervalles sont de fait beaucoup plus longs: 1729-1741, 1741-1751, 1751-1764, et enfin 1765-1790 ${ }^{135}$. C'est dans ce contexte que les portraits de Marie-Thérèse sont réalisés. Ces portraits où les insignes hongrois sont mis en avant prennent alors une signification toute particulière car ils permettent, à leur manière, de compenser les mesures réformatrices prises à la même période par la cour de Vienne. Il s'agit de remplacer et de combler un certain vide politique ainsi que d'apaiser tensions et incertitudes en démultipliant le portrait royal et en mettant en avant les insignes des pays. Désormais, l'interlocuteur privilégié des élites hongroises n'est plus seulement la diète mais Marie-Thérèse. Le contact personnel entre la souveraine et les Hongrois s'instaure, entre autres, par un contact visuel à travers les portraits.

Si le type de portraits comme roi de Hongrie est fortement lié à Vienne et à l'atelier de Meytens, il est aussi diffusé par les nobles, les hôtels de ville et les comitats hongrois qui commandent et reçoivent en priorité ce genre de représentation. Il est important de noter que différentes villes de la Monarchie, comme Vienne (P 126), Prague (P 127, Figure 26), Bolzano (P 29, Figure 17) et Gorizia (P 118), reçoivent des portraits qui mettent en valeur la couronne de Hongrie.

terreichischen Barockmonarchie », pp. 88-89; Seitschek, « Die Pragmatische Sanktion », pp. 237-238; Poór, « Kontroversen », pp. 420-421.

132 Szijártó, «The Diet», p. 153, p. 169; Gergely, «Staatsrechtliche Beziehung », p. 29; Poór, « Kontroversen », p. 430.

133 Gergely, «Staatsrechtliche Beziehung », p. 29.

134 Barta, «Ungarn und die Habsburger im 18. Jahrhundert », pp. 233-234.

135 Barta, «Ungarn und die Habsburger im 18. Jahrhundert », p. 234. 
La représentation hongroise apparaît ainsi comme un élément de reconnaissance et comme un support de légitimité largement diffusé. C'est aussi un message à l'adresse des autres provinces, en particulier le royaume de Bohême, soulignant la fidélité spéciale montrée par les Hongrois ainsi que la faveur particulière dont ils sont censés jouir auprès de la souveraine. Marie-Thérèse n'est certes pas la première de la dynastie à l'utiliser mais elle est la première à s'en servir de cette manière quasi-systématique et avec cette ampleur. Une image exemplaire s'impose à tous à travers la distribution des portraits où les motifs hongrois sont mis en avant.

On peut également attribuer à la mise en valeur de Marie-Thérèse en tant que roi de Hongrie un rôle d'assimilation et d'intégration. En raison des rébellions qui se produisent au cours de l'époque moderne, une tension persiste entre les membres de la noblesse hongroise et les Habsbourg. Bien que les Hongrois soient traditionnellement et souvent en position de rebelles et de vaincus du point de vue de la cour, ou peut-être pour cette raison même, depuis le début du XVIII ${ }^{\mathrm{e}}$ siècle, ils sont mis à l'honneur dans les portraits grâce à leurs symboles. Sous Marie-Thérèse, ils sont en effet en position de sauveurs de la Monarchie. Les portraits témoignent de ces dynamiques et de ces relations d'interdépendance entre la Monarchie et le royaume de Hongrie. Pour Marie-Thérèse, il s'agit, de manière très stratégique, d'intégrer la nation hongroise à la Monarchie, en représentant la Hongrie comme la première des nations. On rend ainsi un hommage particulier à son histoire grâce à la représentation récurrente des symboles locaux.

Nous pouvons distinguer quatre étapes-types iconographiques dans cette représentation : la représentation de Marie-Thérèse en roi de Hongrie, en habit hongrois avec les insignes du couronnement ; la représentation de la souveraine à cheval sur la colline du couronnement ; les portraits de la souveraine sans habit national, mais avec la couronne de Hongrie, seule ou devant les autres couronnes des autres pays ; enfin les portraits de Marie-Thérèse en Grand Maître de l'Ordre de Saint-Étienne ou encore plus fréquemment avec l'insigne de cet ordre. Réunis, ces quatre types occupent une place prédominante dans notre corpus, constituant largement plus de la moitié des tableaux recensés. Le premier type de portraits est certainement le plus marquant, celui où MarieThérèse est représentée avec des habits hongrois et avec la seule couronne de Saint Étienne qu'elle enlace parfois d'un geste protecteur.

Les deux premiers de ces types d'images sont destinés à célébrer et rappeler le couronnement hongrois, premier des couronnements et première des légitimations. Ce fut l'une des rares occasions où Marie-Thérèse fut présente en public, dehors, en Hongrie spécialement, où la population (ou du moins une partie) put la voir de ses propres yeux. Le motif de la souveraine à cheval sur la 
colline de Presbourg, relativement rare, est présent dans quelques portraits répertoriés dans notre corpus, datant surtout du début du règne. Philipp Ferdinand von Hamilton reprend ce motif dans un portrait qui est aujourd'hui dans une collection privée (P 18) ${ }^{136}$. Martin van Meytens, avec son atelier, réalise aussi des portraits équestres vers 1741 et 1742, l'un se trouve notamment au Musée Brukenthal en Roumanie (P 19). Plus tard, en 1747, un dénommé Carl Hirsch réalise un tableau similaire, aujourd'hui dans la Galerie de la ville de Bratislava (P 16) ${ }^{137}$. Dans les cas d'Hamilton et de Meytens, il s'agit de commandes de cour.

Dans ces tableaux, la souveraine, avec son époux en pendant, gravit la colline du couronnement de Presbourg, composée de la terre issue des différents territoires du royaume de Hongrie. Arrivée en haut, la souveraine brandit son épée dans les quatre directions cardinales, vers le nord, vers le sud, vers l'ouest et vers l'est, en signe de protection du royaume quel que soit l'endroit d'où l'ennemi arrive. En 1741, les conseillers royaux insistent en effet sur la valeur et l'importance du couronnement hongrois ${ }^{138}$ : en particulier le moment où MarieThérèse brandit l'épée de Saint Étienne et exécute les signes de croix rituels est considéré comme un élément crucial ; certains attributs comme l'épée sont des éléments masculins ${ }^{139}$.

On retrouve des copies ou répliques du tableau d'Hamilton au château de Gödöllő près de Budapest (P 244) et au Musée National de Budapest ${ }^{140}$, provenant des collections de la famille Jankovich (P 20). Cette scène du couronnement hongrois, devenue presque légendaire, est par ailleurs très largement diffusée en gravure tout au long du règne de Marie-Thérèse ${ }^{141}$.

Puisque la Hongrie est à l'honneur dans les arts quels qu'ils soient, une mise en perspective entre la production littéraire et le portrait de Marie-Thérèse s'avère intéressante. Toute l'activité artistique est en effet imprégnée par les grandes thématiques du règne. C'est ainsi que la Theresias, un poème d'hommage rendu à Marie-Thérèse, est écrit en 1750. Ce poème de félicitation destiné

136 Mraz, « Maria Theresia beim Schwertstreich ».

137 Cet artiste est peut-être à identifier avec le miniaturiste C. Hirsch dont on connaît quelques autres portraits princiers ; voir Schidlof, La miniature en Europe, vol. 1, p. 373.

138 Barcsay, Herrschaftsantritt, p. 206.

139 Hertel, « Maria Theresia als 'König von Ungarn' », p. 115: « Das Schwert war seit der Antike ein weit verbreitetes Symbol für Männlichkeit und Stärke ». Concernant la masculinité de certains attributs dans ces portraits, voir aussi Kuhn, « Das Schwert in der Hand der Frauen », p. 7. 140 Merci au Musée national hongrois de nous avoir fourni ses fiches répertoriant les portraits de leurs collections.

141 Lechner, « Porträtmalerei », pp. 54-55; Mraz, « Maria Theresia beim Schwertstreich »; Polleross, « Austriacus Hungariae Rex », p. 73. 
aux nouveaux bacheliers de l'université jésuite de Trnava est une joute oratoire entre les personnifications des vertus de la souveraine qui rivalisent pour la première place. Le prix est finalement remis à la souveraine elle-même, incarnation de toutes les vertus ${ }^{142}$. Pour le discours de la Majesté, qui succède juste à celle de la Piété, l'auteur László Csapodi choisit comme sujet l'épisode du couronnement de Marie-Thérèse en roi de Hongrie à Presbourg ainsi que l'engagement des Hongrois à soutenir leur reine. Il s'est très ouvertement inspiré de l'exemple de Franz Christoph Scheyb, qui avait lui aussi fait parler l'allégorie de la Majesté au sujet des mêmes évènements comme preuves de la majesté triomphante de la reine ${ }^{143}$.

Les années 1741 et 1742 voient une première vague de portraits de MarieThérèse en roi de Hongrie, autrement dit en habit de couronnement hongrois ou au moins avec la couronne de Saint Étienne. Ce type de représentation peut également être mis sur le compte de la perte de la couronne impériale, entérinée par l'élection et le couronnement du Wittelsbach, Charles VII de Bavière, le 12 février 1742. Dans ce contexte, il s'agit de s'appuyer sur les titres déjà acquis et assurés. Les autorités de la ville de Presbourg commandent en 1742 un portrait de la souveraine pour la salle de conseil de la commune auprès du peintre presbourgeois, Daniel Schmidelli. C'est à notre connaissance l'une des plus anciennes représentations de Marie-Thérèse en roi de Hongrie ( $\mathrm{P}$ 24, Figure 5). Comme nous l'avons évoqué dans la première partie, le peintre est originaire de Presbourg et a étudié à l'Académie de Vienne. Il existe un échange d'influences entre les provinces et le centre viennois. Les traits du visage de la souveraine comme la composition générale du portrait rappellent le style des portraits de Martin van Meytens.

En commémoration du couronnement, Marie-Thérèse est représentée avec les regalia. Tournée de manière presque frontale vers le spectateur, la souveraine tient dans la main droite le sceptre royal, tandis que sa main gauche repose sur la couronne de Saint Étienne, placée sur un coussin rouge, non loin d'un autre insigne du pouvoir, l'orbe avec la double croix ${ }^{144}$. Marie-Thérèse porte sur sa poitrine un portrait en médaillon de son époux, qu'après de nombreuses difficultés, elle a nommé corégent. Au-dessus d'habits somptueux, le manteau de couronnement hongrois repose sur ses épaules. La broderie de cette robe est ornée de perles et d'autres pierres précieuses qui sont elles-

142 Klecker, «Tradition und Moderne », pp. 238-240.

143 Scheyb, Theresiade, livre 3, vers 389-472. Sur l'utilisation de cette même scène dans une troisième panégyrique, voir Klecker, « Maria Theresia und Aeneas », pp. 118-119.

144 Rusina, Baroque ou Barok, The History of Slovak Fine Art, contribution de Marian Zervan, 271, p. 482. 
mêmes issues du traditionnel vêtement de couronnement hongrois. Un portrait très similaire à celui de Presbourg est commandé plus tard, vers 1770, pour la Lothringersaal, salle des Lorraine, du château de la Hofburg à Innsbruck $\left(\mathrm{P}\right.$ 68) ${ }^{145}$. Probablement réalisé par l'atelier de Meytens, ce tableau montre presque exactement la même composition et iconographie, à l'exception de la couronne maintenant placée sur la tête de Marie-Thérèse. Au fil du temps, et même après la conjoncture spécifique du début du règne, la place de la Hongrie dans les portraits de Marie-Thérèse est toujours aussi importante mais change parfois dans sa mise en scène.

À cette image venant de Presbourg en 1742, il est nécessaire de confronter les autres images issues de Vienne et des provinces de la Monarchie. Au même moment, vers 1741-1742, Marie-Thérèse commande des types de portraits similaires. Une incitation réciproque est bien à l'œuvre, même si le modèle de cour ainsi que l'influence du pouvoir royal restent dominants. À travers la commande par Presbourg du portrait de Marie-Thérèse en roi de Hongrie, les Hongrois, ou du moins les autorités urbaines de la capitale, s'approprient l'image royale en reconnaissant Marie-Thérèse comme leur propre souverain.

Martin van Meytens et son atelier exécutent de leur côté plusieurs portraits semblables de Marie-Thérèse en habits de couronnement hongrois et/ou à côté de la couronne de Saint Étienne ${ }^{146}$. On retrouve ces tableaux aujourd'hui à Krems (P 40, Figure 19) et à Sankt Pölten en Autriche (P 41), à Olomouc (P 30) ou au château de Vizovice en République tchèque (P 39, Figure 18) ou même en Allemagne, au château des comtes de Waldeck (P 38). Des copies sont par ailleurs réalisées à partir de la version initiale de Schmidelli (P 24, Figure 5) ${ }^{147}$, on peut les retrouver tout particulièrement en Hongrie, à Budapest, à Gödöllő (P 229), à Bojnice (P 44) mais aussi à Bolzano dans l'actuel Tyrol du Sud (P 29, Figure 17). Même s'il s'agit de la date du couronnement de Marie-Thérèse comme roi de Bohême, une ville un peu excentrée comme Bolzano, qui n'appartient ni au royaume de Bohême ni à celui de Hongrie, choisit de commander en 1743, auprès de l'atelier de Meytens, un portrait de la souveraine comme roi de Hongrie. Plus tard, une inscription en bas à droite du tableau indiquera : Teresa regina dei Boemi, Theresa reine de Bohême ${ }^{148}$. Le premier titre de Marie-Thérèse de roi de Hongrie repré-

145 Oettinger, Kunstdenkmäler Innsbrucks, pp. 144 et 146, Abb. 160.

146 Il existe une gravure de Meytens, à l'Albertina de Vienne, représentant Marie-Thérèse en habit hongrois près de la couronne de Hongrie ; voir Lisholm, Martin van Meytens, numéro de catalogue 62, p. 101.

147 Voir note 249, chapitre III.

148 Trapp, Maria Theresia und Tirol, p. 26; voir aussi Matsche, " Maria Theresias Bild », p. 209. 
sente ainsi un intérêt stratégique reconnu par toutes les élites, non seulement les élites hongroises. Ce sont aussi des villes loin du royaume de Hongrie qui choisissent des iconographies privilégiant les insignes de Hongrie. Dans le cas cité d'Olomouc (P 30), cela relève peut-être d'une volonté morave de se distancer des prétentions de la Bohême et de souligner sa loyauté, en opposition avec la Bohême.

Pour le plus représenté des quatre types de portraits renvoyant à la Hongrie, le portrait en « roi » de Hongrie, on peut constater qu'à l'exception du portrait commandé par la ville de Presbourg auprès de Daniel Schmidelli (P 24, Figure 5), la plupart des portraits de ce type sont des commandes de la cour de Vienne, réalisés par Martin van Meytens et son atelier dans les années 1740. Le centre viennois, par ses peintres notamment, se trouve souvent à l'initiative de la représentation de Marie-Thérèse à la manière noble hongroise, rendant hommage au premier titre de la souveraine. Cette représentation est relayée par les autres pouvoirs.

Notons qu'à la même époque, la femme de son rival, Charles Albert de Bavière, l'impératrice Marie-Amélie, est peinte d'une manière similaire, par rapport cette fois à la couronne impériale. Le tableau de Marie-Amélie, exposé au château de Brühl en Allemagne, a été réalisé par un membre de l'atelier de Meytens, Georges Desmarées ${ }^{149}$. Représentée en pied, Marie-Amélie entoure de sa main droite la couronne impériale, rappelant son rang d'impératrice et son attachement à la dignité impériale. Ce portrait de Desmarées ressemble fortement au portrait de Marie-Thérèse, réalisé par Meytens, et conservé à Krems en Autriche (P 40, Figure 19), dans lequel la main de la souveraine enlace la couronne de Hongrie.

Les mises en scène de la Hongrie dans les portraits de Marie-Thérèse évoluent au gré des rapports de la Monarchie vis-à-vis du royaume de Saint Étienne. L'attitude de Marie-Thérèse envers la Hongrie oscille entre une politique de compromis et de sévérité dissimulée de façon stratégique derrière des mesures spectaculaires ${ }^{150}$. Cela correspond à une politique d'État réelle ainsi qu'à une stratégie de représentation qui peut avoir des répercussions sur la politique de la Monarchie. En mettant en avant la Hongrie par l'intermédiaire de sa couronne, cette stratégie sert les intérêts de la politique viennoise. Les portraits prennent sens dans le cadre de cette politique d'intégration.

149 Hansmann, Das Treppenhaus und das Grosse Neue Appartement des Brühler Schlosses, Nr. 182; Portrait de l'impératrice Marie-Amélie de Georges Desmarées (atelier), Munich, Schloss Nymphenburg, Ny-G 113-Hauptschloß, R. 10. Voir aussi Hertel, Banakas, « Die Gestik Maria Theresias », pp. 206-207.

150 Balázs, « Die Königin von Ungarn »; Mraz, « Maria Theresia als Königin von Ungarn ». 
Les tableaux reflètent les différentes étapes de la relation de Marie-Thérèse et de la Hongrie au cours du règne. Ces étapes sont marquées par le couronnement de 1741, la convocation des diètes en 1741, 1751 et 1764, ainsi que la fondation de l'Ordre de Saint-Étienne en 1764, qui peut être considérée comme l'apogée de la relation entre Marie-Thérèse et la Hongrie. En réalité, la période est marquée par de nombreuses tensions entre les états et la Monarchie, en particulier au niveau financier et fiscal. Le conflit sur la réforme fiscale s'étend au moins entre 1751 et 1764 . Alors que les relations se distendent en pratique entre Vienne et les états hongrois, il s'agit de mettre en scène plus que jamais les éléments et évènements importants de la relation entre la nation hongroise et la Maison d'Autriche, et plus particulièrement Marie-Thérèse. On peut établir un parallèle entre l'augmentation des portraits avec la couronne de Hongrie au premier plan et la politique d'intégration de la cour viennoise. Le 18 avril 1751, Marie-Thérèse convoque la diète à Presbourg qu'elle inaugure en personne le 10 mai. Comme le rappelle Jean Bérenger, le but de cette diète est politique : il s'agit de montrer aux princes européens que les Hongrois se sont réconciliés avec la Maison d'Autriche comme dix ans plus tôt, en $1741^{151}$.

Marie-Thérèse traite ainsi les Hongrois avec une bonté ostentatoire, non dénuée d'arrière-pensées stratégiques, en répandant notamment faveurs et honneurs. Les portraits réalisés dans les années 1750, moment de relatif renforcement du pouvoir monarchique, montrent les couronnes les unes à côté des autres, c'est-à-dire de manière inséparable. Marie-Thérèse est ainsi représentée en robe de cour à côté de la couronne de Hongrie, qui est peinte seule ou devant les autres couronnes. La couronne de Saint Étienne occupe souvent le premier plan comme dans le portrait P 65 à Litomyšl en Bohême où la souveraine apparaît en pied, appuyée sur le sceptre, la couronne de Saint Étienne devant les autres couronnes. En échange de compensations, la Hongrie est le premier royaume à accepter de rester uni aux Habsbourg au début du règne. Le royaume respecte ainsi la Pragmatique Sanction.

Depuis 1758, Marie-Thérèse se désigne comme apostolische Erbkönigin, reine apostolique ${ }^{152}$. Elle se place ainsi en position d'héritière dynastique et légitime du roi apostolique et vénéré Saint Étienne. Cette nouvelle désignation se reflète dans les tableaux en représentant la couronne de Saint Étienne devant les autres couronnes de manière systématique. Par ailleurs, l'épée, symbole masculin ${ }^{153}$, et la double croix qui est représentée dans certains portraits,

151 Bérenger, Kecskeméti, Parlement et vie parlementaire, p. 215.

152 Galavics, « Die Künstlerische Repräsentation », p. 16; Evans, « Maria Theresia and Hungary », p. 196.

153 Hertel, « Maria Theresia als ‘König von Ungarn’ », p. 115. 
comme dans celui du château de Gödöllő, soulignent le titre de reine apostolique détenu par Marie-Thérèse (P 229).

Dans les années 1750, après les couronnements, la souveraine est peinte de manière récurrente avec son premier titre de roi de Hongrie comme l'atteste le portrait, aujourd'hui au Musée de la ville de Vienne, réalisé par Meytens (P 126), pour l'hôtel de ville. Il représente la souveraine à côté de la seule couronne hongroise. Cette version originale a servi de modèle à plusieurs répliques qui se trouvent au Musée de la ville de Prague (P 127, Figure 26) et au Landhaus de Basse-Autriche à Vienne (P 128, Figure 27), aujourd'hui Landesmuseum de Basse-Autriche ${ }^{154}$, commandés par les autorités locales elles-mêmes, autorités qui ne sont pas d'origine hongroise mais n'en continuent pas moins à diffuser cette image convenue et connue de Marie-Thérèse. Le modèle original est commandé et réalisé peu avant la seconde diète hongroise de 1751. MarieThérèse n'est pas représentée en costume traditionnel hongrois mais dans une somptueuse robe de soie rose brodée de dentelles. Elle s'appuie sur un sceptre, souveraine, en position dominante. Seule couronne présente, la couronne hongroise repose sur un coussin à ses côtés. Le portrait ne vise donc pas tant à rappeler concrètement le couronnement de Presbourg, il est plutôt destiné à présenter la nation hongroise comme la première des nations et à souligner le premier titre de Marie-Thérèse comme roi de Hongrie. Même avec des habits de cour qui ne font pas forcément référence à la Hongrie, Marie-Thérèse est représentée avec la seule couronne de Hongrie, à une période où pourtant ses titres sont acquis. Elle a été couronnée roi de Hongrie en 1741, roi de Bohême en 1743 et son époux a été élu et couronné à la tête du Saint Empire en 1745.

Un autre modèle encore, légèrement différent des précédents mais presque équivalent pour sa signification politique, est fourni par le portrait commandé par l'Académie de Vienne pour orner sa salle de réception (P 130 $)^{155}$, représentant Marie-Thérèse appuyée sur son sceptre à côté de la couronne de Hongrie. Ce modèle est diffusé par des copies assez similaires, à Bojnice en Slovaquie (P 129) notamment ${ }^{156}$.

154 Krug, « Denkmäler », pp. 231-233.

155 Lechner, « Maria Theresia als 'König' von Ungarn »; voir aussi Banakas, « Maria Theresia als 'König' von Ungarn ».

156 Précisons que des portraits très similaires à celui de l'Académie de Vienne se trouvent aussi à Buda (P 132) et à Prague. Ces portraits qui montrent exactement la même posture représentent cependant la souveraine à côté de la couronne impériale familiale. 
Modèle de Marie-Thérèse, sceptre en main avec la couronne de Saint Étienne: un même modèle de portraits pour des destinataires différents

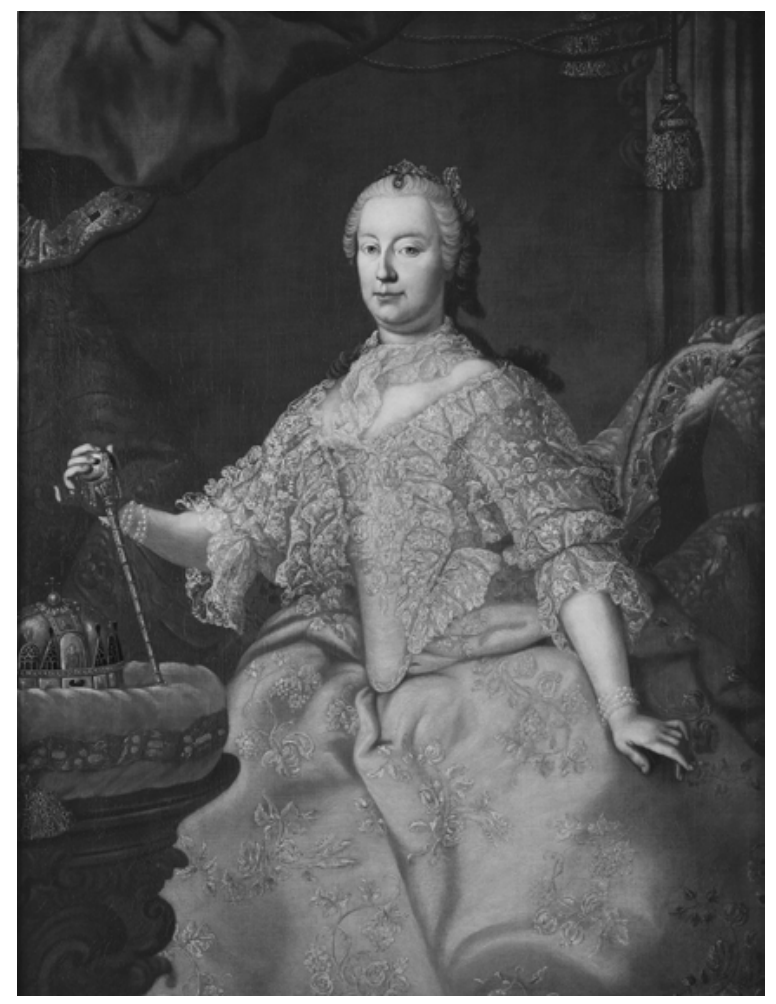

Figure 26: Martin van Meytens, Marie-Thérèse, années 1750, 143, 8 x 109, 7 cm, HD 001 529, Musée de la ville de Prague, République tchèque. Collections du Musée. The City of Prague Museum.

Ce portrait se trouve au Musée de la ville de Prague (P 127, Figure 26), commandée probablement dans les années 1750 et en provenance de la guilde des bouchers de la ville. C'est exactement le même portrait que celui de Vienne (P 126), avec la même robe ${ }^{157}$, le même positionnement de la main droite sur le sceptre, la même couronne de Saint Étienne représentée sur une table à côté de la souveraine.

157 Baum, Katalog des Österreichischen Barockmuseums, vol. 2, pp. 427-430. 


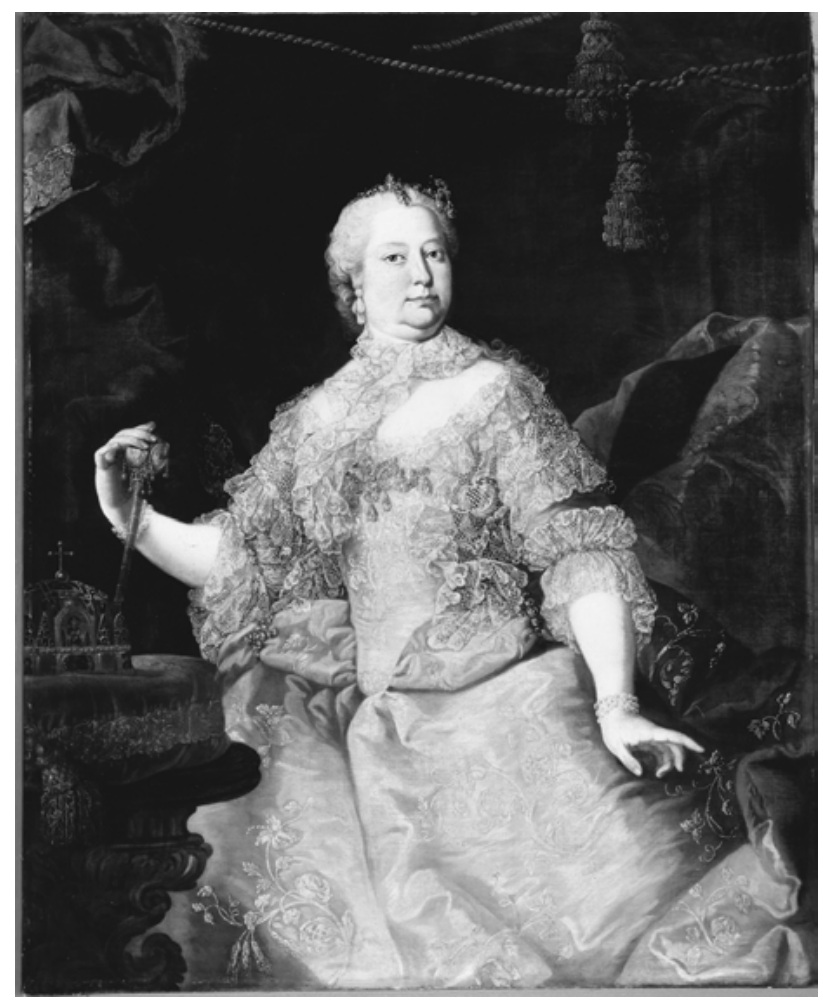

Figure 27: Atelier de Martin van Meytens, Marie-Thérèse, vers 1760, 154 x 116 cm, Inv. Nr. 1996, Landesmuseum Niederösterreich, ( Landessammlungen NÖ, Photo : Christoph Fuchs, Autriche.

Enfin, un autre portrait commandé par la Maison des états de Basse-Autriche à Vienne pour sa salle d'audience, réalisé vers 1760 par l'atelier de Martin van Meytens ( $\mathrm{P} 128$, Figure 27), est une réplique des portraits précédents conservés à Vienne (P 126) et à Prague (P 127, Figure 26), à la différence près que le corps et en particulier le visage de Marie-Thérèse semblent s'être encore alourdis. Ces répliques d'un même portrait peuvent être lues comme une forme de concurrence, mais surtout d'émulation, pour l'acquisition d'un type de portrait similaire.

Les types de portraits qui montrent Marie-Thérèse en habits de cour, à côté de la couronne hongroise ou en habits de couronnement hongrois comme au début du règne, connaissent un regain d'intérêt dans les années 1750-1760. En juin 1764, la dernière diète hongroise du règne a lieu à Presbourg. Les antagonismes s'accentuent entre la cour et les états hongrois, en particulier au sujet de l'augmentation des impôts. Les états refusent d'accorder à la souveraine un 
accroissement des charges ${ }^{158}$. Marie-Thérèse suspend alors leur convocation. Elle décide dorénavant de dicter ses volontés aux comitats au moyen de lettres patentes, de manière plus directe ${ }^{159}$.

Si la représentation des insignes hongrois ou en tant que roi couronné, repris d'un motif du début du règne, réapparaît à cette époque, cela peut être considéré comme un moyen d'apaiser les élites hongroises en les intégrant au sein de la Monarchie, au moment où la situation est particulièrement tendue. Marie-Thérèse promeut et soutient les traditions nationales hongroises en cette même année 1764 avec la fondation de l'Ordre de Saint-Étienne. Deux portraits la représentent en Grand Maître de l'Ordre, l'un est dans la Salle des Géants de la Hofburg d'Innsbruck $^{160}$ peint probablement par Wenzel Pohl (P 72) ${ }^{161}$, l'autre au Kunsthistorisches Museum de Vienne, par un auteur inconnu (P 230, Figure 38) ${ }^{162}$.

Nous pouvons faire un lien avec les scènes d'histoire de la chancellerie qui mettent en valeur les plus grands évènements de l'histoire du règne de MarieThérèse avec la Hongrie. Contrairement à la chancellerie de Bohême, celle de Hongrie reste indépendante. En 1747, le palais de la chancellerie est même rénové à partir des fonds réunis par les comitats et par les villes libres royales ${ }^{163}$. Sur le mur de la chancellerie, les tableaux montrent le palatin Lajos Battyhány qui reçoit des mains de Marie-Thérèse la grande croix de l'unique ordre de fondation hongroise. Cette remise se fait en présence du chancelier Ferenc Esterházy et de Karl Friedrich comte de Hatzfeld, le président de la Hofkammer ${ }^{164}$. Ferenc comte Barkóczy, archevêque de Gran, ainsi que le futur empereur Joseph II sont les premiers à porter cet ordre aux côtés de Batthyány et du chancelier Esterházy. Après les rénovations du palais, les six tableaux du

158 Ember, «Der österreichische Staatsrat und Ungarn », p. 51.

159 Szabo, Kaunitz and Enlightened Absolutism, p. 313, pp. 325-328; Ember, « Der österreichische Staatsrat und Ungarn », pp. 51-52; Ember, « Der österreichische Staatsrat und die ungarische Verfassung », p. 119; Bérenger, La Hongrie des Habsbourg, vol. 1, p. 220, pp. 225-226.

160 Voir entre autres l'ouvrage de Hanzl-Wachter, Hofburg zu Innsbruck. L'auteur recense à la fin de son ouvrage les inventaires du château datant de 1773 et de 1778 où des portraits de Marie-Thérèse et de son époux sont déjà enregistrés dans les salles d'audiences. S'agit-il des mêmes portraits que ceux exposés aujourd'hui ? On ne peut l'affirmer avec certitude.

161 S'agit-il de Wenzel Pohl ou de Jacob Kohl ? Selon les dernières recherches de Julianna Papp, il s'agirait de Wenzel Pohl.

162 Kugler, « Kaiserin und Königin Maria Theresia ».

163 Fazekas, « Die Ungarische Hofkanzlei », pp. 496-498; sur la rénovation du bâtiment, voir aussi Galavics, « Die Künstlerische Repräsentation », pp. 15-16.

164 Sur Hatzfeld, président de 1765 à 1771, sous lequel le pouvoir de la Hofkammer est beaucoup accru, voir Dickson, Rauscher, « Die Hofkammer im 18. Jahrhundert », pp. 852-853. 
couronnement hongrois de 1741, scènes d'histoire, réalisés par Franz Messmer et Wenzel Pohl, sont installés dans la salle d'audience du chancelier en $1768^{165}$.

Concernant la représentation en habit de couronnement hongrois, des années après la cérémonie de 1741, le portrait du château d'Esterháza à Fertőd (P 69, Figure 6), qui date des années 1750, montre la souveraine en robe de couronnement hongrois comme au début du règne avec, en plus, la couronne sur la tête. Le peintre Johann Baptist Glunck (P 69, Figure 6) ${ }^{166}$ s'est probablement inspiré du célèbre portrait réalisé par Schmidelli en 1742 (P 24, Figure 5). Il existe d'autres tableaux similaires à Gödöllő (P 229), au château de Bojnice (P 44) et au Musée National hongrois de Budapest mais aussi à la Hofburg d'Innsbruck (P 68). Dans le portrait de Fertőd, les traits vieillis, le visage alourdi, de la souveraine reflètent le corps naturel de Marie-Thérèse qui se transforme au fil des années, tandis que l'habit de couronnement et les symboles hongrois incarnent le versant politique et symbolique du corps de Marie-Thérèse, qui eux restent les mêmes et ne changent pas malgré les années. Marie-Thérèse tient le sceptre dans la main droite et pose sa main gauche sur l'orbe. L'épée est à côté de l'orbe sur une table, ces objets sont délicatement couchés sur un coussin de velours rouge.

\section{Évoquons aussi le portrait de Győr représentant Marie-Thérèse en « roi » couronnée de Hongrie}

Dans les années 1750-1760 comme tout au long du règne, lorsqu'il s'agit de mettre de nouveau en avant le corps politique et royal de Marie-Thérèse, notamment vis-à-vis de la Hongrie, alors que la diète hongroise s'apprête de nouveau à être rassemblée, les peintres représentent de nouveau la souveraine en roi de Hongrie, la couronne sur la tête à la manière d'un roi et non sur l'épaule telle une reine, comme dans ce portrait qui se trouve à Győr en Hongrie ( $\mathrm{P} 43$, Figure 28$)^{167}$. Nous pouvons dater ce portrait des années 1750 , en raison du léger changement dans le corps naturel de la souveraine, ce qui laisserait supposer qu'elle a avancé en âge. Marie-Thérèse est ainsi montrée dans sa fonction première et principale de roi de Hongrie. Même si ses traits sont altérés et si son visage a quelque peu grossi, les éléments principaux du couronnement hongrois sont mis en valeur, de manière tout aussi, si ce n'est encore plus marquante

165 Galavics, « Barockkunst », pp. 63-65.

166 Ou s'agit-il de B. Ilye Glunck comme il est mentionné dans l'inventaire du château qui le conserve ? Voir principalement Serfőző, « Repräsentation Maria Theresias in Ungarn », p. 314, qui offre de plus amples informations sur ce portrait.

167 Ce portrait nous fait penser à celui de Glunck, P 69, Figure 6. 


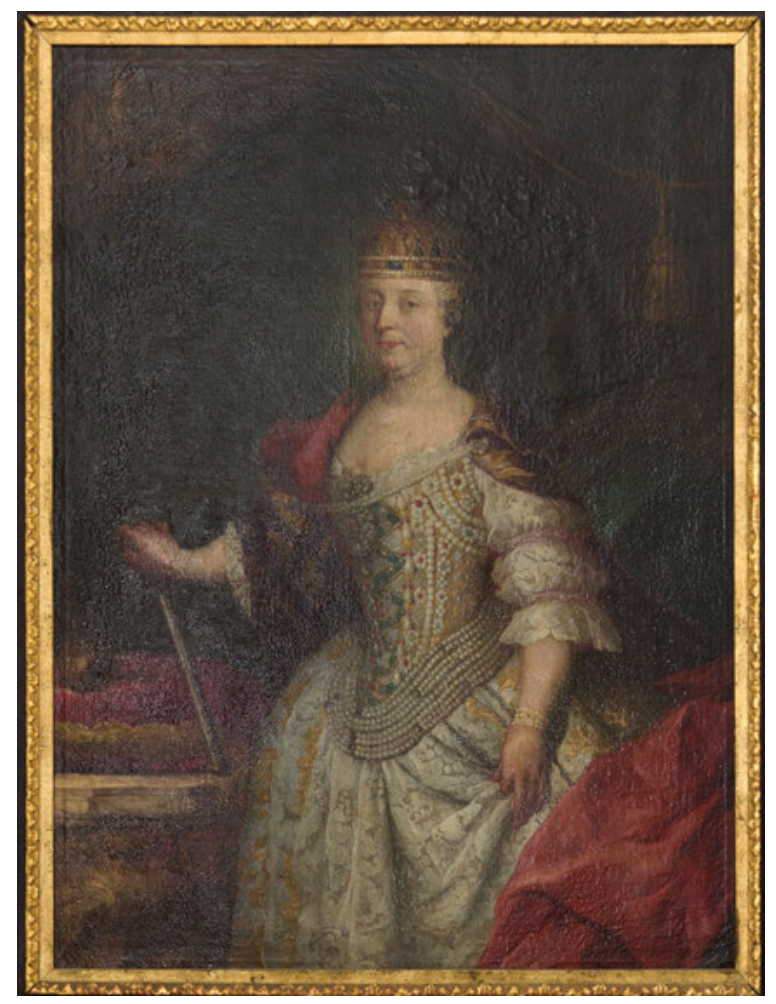

Figure 28: Auteur inconnu, Marie-Thérèse, après 1741, probablement dans les années 1750 , 150 x 113 cm, K. 65. 19. 1, Xántus János Múzeum, Győr, Hongrie. Rómer Flóris Múvészeti és Történeti Múzeum.

qu'au début du règne. La souveraine est peinte la couronne de Saint Étienne sur la tête, couronne légèrement mise en lumière par le peintre.

La mise en valeur des symboles hongrois correspond à un projet de grande envergure qui dépasse largement le support et le cadre des portraits royaux de Marie-Thérèse, ce qui amène à évoquer le terme d'exemple hongrois, adressé aux Hongrois comme aux autres pays de la Monarchie. Cela est déjà confirmé par le projet politique à l'origine du sarcophage de Marie-Thérèse et de François Étienne, réalisé par Balthasar Ferdinand Moll $^{168}$. Ce programme immortalise le parcours et glorifie l'apogée du pouvoir politique du couple impérial. François

168 Voir à ce sujet Telesko, Maria Theresia, pp. 90-109 et le travail de Hawlik-van de Water, Die Kaisergruft in Wien und ihre Geschichte. 
Étienne est représenté comme empereur, d'une manière atemporelle, en habits d'imperator romain ${ }^{169}$ tandis que Marie-Thérèse est sculptée en roi de Hongrie avec les insignes de sa dignité royale.

Si la réforme gouvernementale du conseiller Haugwitz ne touche en 1749 que les pays d'Autriche et de Bohême, à partir de 1761, le point central de la politique intérieure se déplace progressivement vers la Hongrie ${ }^{170}$. Ces pays concentrent désormais l'attention des dirigeants comme celle du chancelier Kaunitz. Dès 1761, Kaunitz recommande à Marie-Thérèse de ne plus rassembler la diète mais de s'adresser directement aux comitats ${ }^{171}$. Après la tentative infructueuse de 1764 , elle ne la convoque plus jusqu'à sa mort ${ }^{172}$. Durant cette dernière période, les quinze dernières années du règne, les portraits et les visites de la souveraine se multiplient sur le territoire hongrois ${ }^{173}$. Ces mesures expliquent à leur façon l'importance prise par les symboles hongrois dans les portraits de Marie-Thérèse, importance qui semble s'accroître au cours du règne en particulier dans les années 1760 . Les portraits où la souveraine tient un document en main, particulièrement nombreux en Hongrie durant la dernière décennie du règne, soulignent ce mouvement de réformes. À sa manière, Marie-Thérèse tient la situation en main, on peut peut-être y lire un renouvellement du diplôme inaugural dans un sens positif pour le pouvoir royal - du moins est-ce une supposition de notre part. Est-ce un moyen de rappeler que la souveraine est toujours engagée par le diplôme inaugural de couronnement, qu'elle s'engage elle-même vis-à-vis de la Hongrie, mais que c'est désormais elle qui donne le ton ? Si notamment le Musée Červený Kameň en Slovaquie présente plusieurs portraits de Marie-Thérèse avec ce papier en main ${ }^{174}$, on retrouve aussi ce type de tableaux sur l'ensemble des territoires de la Monarchie.

169 Il porte l'Ordre de la Toison d'Or et il est habillé tel un imperator romain.

170 Ember, "Der österreichische Staatsrat und Ungarn », p. 46.

171 Szabo, Kaunitz and Enlightened Absolutism, p. 313.

172 Barta, « Ungarn und die Habsburger im 18. Jahrhundert », p. 234.

173 Une des grandes initiatives de Marie-Thérèse en Hongrie a pour objet la condition paysanne. La patente urbariale de 1767 codifie et réglemente les relations entre seigneurs et paysans. La patente est mal acceptée par les seigneurs, entre autres parce qu'elle est promulguée sans le consentement de la diète. Même si la condition paysanne semble s'améliorer, l'Urbarium de 1767 ne met pas en place un système nouveau, parce qu'il accepte la tradition seigneuriale, et n'en élimine pas les excès. Nous nous appuyons fortement sur les propos de Bérenger, voir Bérenger, Joseph II, p. 449; Kállay, « Die Reformen », pp. 77-79; Mraz, « Maria Theresia als Königin von Ungarn », p. 19; Seedoch, « Die Urbarialregulierung ».

174 Il existe plusieurs portraits de Marie-Thérèse représentée de cette manière dans les anciennes collections des grandes familles hongroises de la Monarchie. Nous reviendrons sur cette question dans le chapitre $\mathrm{X}$. 
Pour relever les forces de la Maison d'Autriche, " il faut songer à des moyens pour rendre le grand et beau royaume de Hongrie plus heureux pour lui-même et plus utile pour le souverain », écrit Kaunitz en 1761. Il rajoute également que « le pouvoir de la Maison royale serait doublé et de grandes ressources pour un sage gouvernement pourraient être retirées de la Hongrie si elle pouvait être mieux intégrée au sein de la Monarchie ${ }^{175}$. Cet intérêt pour ce pays ainsi que pour les symboles hongrois relève donc d'une véritable politique étatique, que cet intérêt émane de la souveraine ou des grands politiciens et soutiens de son État ${ }^{176}$. Dans un contexte de séparation toujours plus grande entre le Saint Empire et les pays héréditaires, représenter la Hongrie, qui ne fait pas partie de l'Empire, peut être interprété comme une manière de faire oublier la perte de la Sainte Couronne impériale entre 1742 et 1745, et surtout le fait que le roi de Hongrie n'est plus la même personne que l'empereur du Saint Empire. Quant au royaume de Bohême, il reste un fief de l'empereur. L'avantage du royaume de Hongrie, en particulier de la Sainte Couronne de Hongrie, est de ne pas être inféodé à l'Empire. Il offre une autre légitimité indispensable à MarieThérèse surtout durant cette période de partage des rôles entre l'empereur et la souveraine des territoires héréditaires.

Si la proximité de la souveraine avec la Hongrie est incontestable, la place des autres royaumes au sein de la Monarchie transparaît également dans les portraits.

175 Énoncés de Kaunitz au Conseil d'Etat à deux occasions distinctes en 1761, citées chez Ember, « Der österreichische Staatsrat und Ungarn », p. 50: « Wenn dem durchleuchtigsten Erzhaus recht aufgeholfen werden soll, so muss auf Mittel gedacht werdendas grosse und schöne Königreich Hungarn vor sich glücklicher und vor den Souverain nützbarer zu machen ». Et plus tard: « Wann das grosse und fruchtbare Königreich Hungarn in eine rechte Verfassung gesetzt werden könte, so würde die Macht des durchleuchtigsten Erzhauses verdoppelt, und die grösste Resourcen einer weisen Regierung wären aus demselben zu ziehen ». Voir aussi Balázs, « Die Königin von Ungarn », p. 101.

$176 \mathrm{Au}$ moment même où le pouvoir de la Monarchie se resserre sur le royaume de Hongrie, Marie-Thérèse prend un ensemble de mesures symboliques très fortes en faveur des Hongrois. En 1771, la souveraine fait ainsi rentrer de Raguse en Dalmatie (aujourd'hui Dubrovnik) vers Buda la Sainte Dextre, la relique du bras droit du roi Saint Étienne, fondateur du royaume de Hongrie, ce qui est un geste symbolique et politique très fort en direction de la Hongrie. Voir notamment Farbaky, « Le palais royal de Buda », p. 55; Marie-Thérèse s'inscrit dans une continuité familiale, certes, mais sa relation très personnelle et exceptionnelle avec les Hongrois tout au long de son règne, rend sa situation particulièrement inédite. N'oublions toutefois pas de préciser que c'est aussi une manière pour Marie-Thérèse de " mettre la main " sur les symboles hongrois en se positionnant comme leur garante et leur protectrice. Voir notamment Serfőzo,, « 'Männlich' und mächtig ». Voir aussi Galavics, « Ahnen, Helden, Heilige », p. 778 et Galavics, « Die Künstlerische Repräsentation », p. 16. 


\section{c. La Bohême}

La couronne de Hongrie n'est pas le seul insigne d'un pays de la Monarchie représenté dans les tableaux. Les insignes et symboles de Bohême, notamment la couronne, sont aussi montrés, bien que moins fréquemment que ceux de Hongrie et en règle générale en seconde position par rapport à la couronne de Saint Étienne. La couronne de Bohême est associée avec celle d'Autriche, les deux symboles apparaissent côte à côte et en arrière-plan par rapport à la couronne de Hongrie ou parfois à la couronne impériale familiale. Pour le règne de MarieThérèse, l'étude de la Bohême et de l'Autriche appelle, semble-t-il, une analyse commune sur certains points comme sur le processus d'unification et de dépendance par rapport au centre impérial. La dissolution des chancelleries de Bohême et d'Autriche et la création d'institutions communes, le Directorium in publicis et cameralibus et la Oberste Justizstelle, a lieu en $1749^{177}$. En 1761 se met en place une nouvelle administration, la Vereinigte Böhmisch-Österreichische Hofkanzlei, la chancellerie unifiée de Bohême et d'Autriche ${ }^{178}$. Ces réformes administratives traduisent une nette perte d'autonomie pour les pays de la couronne de Bohême, dont l'étendue et l'importance au sein de la Monarchie se sont sensiblement réduites à cause de la conquête prussienne de la plus grande partie de la Silésie. Ce groupe de provinces reste néanmoins d'un poids incontournable sur le plan économique et possède encore des atouts sur le plan politique. Pour le symbolisme des portraits, un élément significatif repose dans le fait que le roi de Bohême est aussi l'un des électeurs du Saint Empire romain germanique $^{179}$.

Cette Kurwürde de Bohême est confiée en fief par l'empereur et l'Empire au roi de Bohême. Les pays de la couronne de Bohême sont toutefois considérés comme souverains et ne sont pas soumis à l'Empire allemand ${ }^{180}$. Depuis 1555 sous Ferdinand $\mathrm{I}^{\mathrm{er}}$, l'empereur et le roi de Bohême sont une seule et même personne. La couronne de Bohême est ainsi souvent représentée avec la couronne impériale dans les portraits où Marie-Thérèse est peinte en habit de couronne-

177 Les deux chancelleries sont réunies dans la Oberste Justizstelle, ayant d'abord été dénuées de leurs compétences non judiciaires, voir Mat’a, " Die Böhmische (Hof-) Kanzlei », pp. 481-482.

178 Hochedlinger, « Die Böhmisch-Österreichische Hofkanzlei », pp. 565-566; Uhlî̌r, « Kaunitz und die böhmischen Länder ».

179 Begert, Böhmen, pp. 480-484.

180 Voir la déclaration de Marie-Thérèse à ce sujet, « Generalinstruktion für den kurböhmischen Komitialgesandten Trautmansdorff » (1780), in Aretin von, Heiliges Römisches Reich, vol. 2, p. 32. Voir aussi Begert, Böhmen, pp. 538-539, 546. 
ment de Bohême. Il s’agit en règle générale de portraits commandés par la cour. En 1743 et 1772, la représentation officielle voulue par la souveraine, s'approprie symboliquement les insignes nationaux, et rappelle ainsi le lien entre l'Empire et la couronne de Bohême, et donc entre les pays héréditaires et la dignité impériale, réunis tous ensemble par le monarque Habsbourg. La raison de l'association fréquente des deux couronnes est spécifiquement la dignité électorale associée à la couronne de Bohême. C'est le seul titre des Habsbourg qui leur permet de participer à l'élection de l'empereur, et ce fait revêt une importance accrue dans les années 1740 lorsqu'il s'agit de regagner la dignité impériale perdue. Le titre de roi de Bohême est donc en quelque sorte la voie à la couronne du Saint Empire.

La couronne de Bohême, également nommée couronne de Saint Wenceslas, et dont la mention remonte au $\mathrm{XIV}^{\mathrm{e}}$ siècle, est constituée de quatre parties, sur lesquelles ont peut admirer des pierres précieuses. Au sommet de la couronne se trouve une croix dorée, avec comme inscription sur les bords extérieurs de la croix : «Hic est spina de Corona Domini », « l'épine de la couronne du seigneur est ici ${ }^{181}$.

Comme ses pères, Marie-Thérèse conserve les insignes de la couronne dans la Schatzkammer viennoise. Elle s'est exprimée au sujet de la couronne de Saint Wenceslas un peu avant son couronnement en tant que roi de Bohême en mai 1743, auprès de Philipp Kinsky : « la couronne est ici, je l'ai portée, plus lourde que celle de Presbourg, elle ressemble à un bonnet de fou ${ }^{182}$. Cette opinion négative $^{183}$ est certainement mêlée au ressentiment à l'égard de certains grands issus de Bohême qui se sont alliés contre elle et auxquels elle a fini par pardonner ${ }^{184}$.

Comme pour le modèle de portraits hongrois, il est nécessaire de mettre en perspective les portraits représentant la souveraine avec l'habit de couronnement ou la couronne de Bohême, avec ceux d'autres rois Habsbourg antérieurs

181 Schwarzenberg, Die Sankt Wenzels-Krone, pp. 18-20, 20 et 26-27, 27, selon l'auteur, il devient de plus en plus habituel de représenter la véritable couronne de Saint Wenceslas (ou Venceslas) sur les armoiries du pays; Cibulka, Die Krönungskleinodien.

182 Walter, Maria Theresia, p. 33: «Die Kron ist hier, habe selbe aufgehabt, ist schwerer als die von Presburg, sehet einem Narrenhäubel gleich ». Voir aussi Arneth, Geschichte Maria Theresias 1742-1744, vol. 2, p. 514.

183 Si Barbara Stollberg-Rilinger mentionne aussi ce mot de la souveraine, elle doute cependant que Marie-Thérèse ait vraiment autant méprisé et sous-estimé l'importance de la couronne de Bohême. Rappelons que Charles Albert de Bavière n'avait pas pu se faire couronner avec la couronne de Saint Wenceslas, conservée dans la Schatzkammer de Vienne ; voir Stollberg-Rilinger, Maria Theresia, p. 103.

184 Toutefois, elle n'oublie pas de réformer ces états en limitant leur pouvoir ; Schwarzenberg, Die Sankt Wenzels-Krone, pp. 55-56. 
à Marie-Thérèse. Sur une huile sur toile de Hans von Aachen, Matthias II en habit de couronnement de Bohême est représenté avec une couronne sur la tête, un orbe dans la main gauche et un sceptre dans celle de droite ${ }^{185}$. Le portrait de son père Charles VI en habit de couronnement de Bohême, lui aussi avec la couronne sur la tête et le sceptre dans la main droite, est plus proche encore de Marie-Thérèse ${ }^{186}$. La couronne impériale est représentée sur un coussin à sa droite, de la même manière que pour Marie-Thérèse dans un portrait de 1743 (P 74). Les deux tableaux peuvent être attribués à Martin van Meytens et se trouvaient ensemble à Vienne à l'ancienne chancellerie d'État (Staatskanzlei), aujourd'hui la chancellerie fédérale (Bundeskanzleramt). Représentée en tant que roi de Bohême, Marie-Thérèse porte le sceptre exactement de la même manière que son père. Sur la table, à ses côtés, la couronne impériale est peinte avec la couronne de Hongrie. Cette dernière n'est pas représentée à côté de Charles VI car elle n'a pas la même importance pour Charles VI que pour Marie-Thérèse. Le château d'Eckartsau conserve également un portrait de l'impératrice Élisabeth Christine, la mère de Marie-Thérèse, arborant sur la tête également la couronne de Bohême tandis que sa main est dirigée en direction de la couronne impériale ${ }^{187}$. En tant qu'épouse du souverain, Élisabeth Christine ne porte ni sceptre, ni habit de couronnement. Dans ses propres portraits, MarieThérèse s'inscrit dans une tradition à la fois masculine et féminine ${ }^{188}$.

Contrairement à la représentation hongroise dont s'emparent toutes les élites, pas seulement celles de Hongrie, la représentation de Marie-Thérèse en tant que roi de Bohême, à côté de la seule couronne de Saint Wenceslas, est beaucoup moins présente dans le corpus de tableaux. Ce type de tableaux est principalement destiné à un public issu de Bohême. Certes, la couronne de Bohême apparaît dans plus de la moitié des portraits du corpus, mais toujours près du chapeau archiducal autrichien, derrière la couronne de Hongrie, dans une posture secondaire. Dans quelques portraits seulement, les insignes du royaume de Bohême sont explicitement mis en valeur. La couronne de Saint Wenceslas n'est donc pas prioritairement mise en avant d'un point de vue pictural.

Le corpus dispose de deux portraits de Marie-Thérèse en habit de couronnement de Bohême, très similaires. L'un, celui de 1743, qui vient d'être mentionné, était autrefois accroché dans l'ancienne chancellerie de Bohême (P 74) ${ }^{189}$, au

185 Schwarzenberg, Die Sankt Wenzels-Krone, Figure 25.

186 Schwarzenberg, Die Sankt Wenzels-Krone, Figure 7.

187 Schwarzenberg, Die Sankt Wenzels-Krone, Figure 26.

188 Schwarzenberg, Die Sankt Wenzels-Krone, Figure 7 et 26.

189 Merci à Friedrich Polleroß pour cette information. 
moment du couronnement de la souveraine en tant que roi de Bohême ${ }^{190}$. L'autre date de 1772, lors de l'agrandissement et de la rénovation du château de Prague (P 76, Figure 30). Ce dernier portrait est exposé avec les autres tableaux des Habsbourg-Lorraine dans la salle familiale du château impérial de la capitale de la Bohême.

Ce nouveau portrait de Marie-Thérèse avec la couronne de Bohême et en habit de couronnement ressemble à s'y méprendre à la version de 1743 attribuée à Meytens. Le peintre, issu du cercle du peintre de cour Auerbach, s'inspire alors du modèle réalisé quelques décennies plus tôt par Meytens. Principale différence, dans la version de 1772, au contraire de celle de 1743, la couronne hongroise a disparu. Seules restent la couronne de Bohême ainsi que la couronne impériale. En tant qu'électrice (Kurfürstin) du Saint Empire et détentrice de la Kurwürde, de la dignité électorale, la souveraine, en sa qualité de roi de Bohême, a le droit de participer à l'élection de l'empereur du Saint Empire romain germanique. Quelques portraits de Marie-Thérèse en habit de couronnement de Bohême placent ainsi la couronne impériale à côté de la souveraine.

En Bohême principalement, et à Prague surtout, on retrouve d'autres portraits de Marie-Thérèse avec la couronne de Bohême ou avec l'habit du couronnement. Ces tableaux sont issus pour la plupart de Vienne, attribuables à des artistes de cour comme Meytens ou Auerbach ou aux membres de leurs ateliers, manifestement destinés à un public issu de Bohême. Vienne destine donc des tableaux à un public de Bohême, comme beaucoup d'autres portraits de MarieThérèse en habit de couronnement hongrois sont principalement peints pour un public hongrois. De ces portraits où la couronne de Bohême est au premier plan, l'un se trouve à la Galerie nationale de Prague (P 73, Figure 29), deux au Musée national (Národní Muzeum, P 232 et P 236), ainsi qu'un autre à l'abbaye bénédictine de Břevnov (P 77). Ils représentent Marie-Thérèse en habit de cour, avec la seule couronne de Bohême.

Il arrive qu'en arrière-plan soient peintes des scènes de bataille rappelant les combats autour de Prague durant la guerre de Succession d'Autriche. C'est le cas du portrait à la Galerie nationale (P 73, Figure 29), exécuté par un artiste autrichien au début des années 1740, destiné très certainement à un public de Bohême. Malgré le ralliement de certains membres de la noblesse de Bohême à Charles Albert de Bavière ${ }^{191}$, Marie-Thérèse opte finalement pour une attitude indulgente vis-à-vis des rebelles. Ces tableaux réalisés dans les années 1740,

190 Mraz, Mraz, Maria Theresia, pp. 81, 347.

191 Concernant l'hommage sans couronnement à Charles Albert à Prague en 1741, voir Berning, Nach alltem löblichen Gebrauch, pp. 170-179. 
exécutés dans le cadre bien particulier de reconquête et d'apaisement du pays, côtoient en Bohême d'autres types de portraits de Marie-Thérèse, en roi de Hongrie par exemple.

En décembre 1741, après la chute de Prague, Marie-Thérèse avait énoncé que sans la Bohême, « je serois une pauvre princesse », et qu'elle était donc convaincue "qu'il faut tout risquer et perdre pour soutenir la Bohême " ${ }^{192}$. L'occupation de la capitale par les troupes françaises et bavaroises dure un peu plus d'une année ; Prague capitule finalement le 2 janvier 1743 et se retrouve entre les mains des Autrichiens. Marie-Thérèse peut alors être couronnée roi de Bohême. Comme le rapporte Benita Berning, les projets pour le cérémoniel et pour les festivités sont surtout calqués sur le couronnement de Charles VI, vingt ans auparavant, et cette émulation de l'exemple paternel correspond au souhait personnel de la reine ${ }^{193}$. Le champ devant la ville où Marie-Thérèse est reçue par les états lors de son arrivée correspond à l'emplacement précis où l'empereur Charles avait été salué en son temps ${ }^{194}$. La continuité est donc claire entre Marie-Thérèse et son père, Charles VI.

Le portrait de Marie-Thérèse réalisé par l'atelier de Meytens vers 1743, aujourd'hui à la Galerie nationale de Prague représente Marie-Thérèse avec la couronne de Bohême au premier plan, on aperçoit derrière la couronne hongroise, et une scène de bataille en arrière-plan (P 73, Figure 29 $)^{195}$. En effet, le couronnement de Bohême n'a eu lieu qu'en 1743, soit deux ans après le couronnement de Hongrie. La prise de distance de certains membres de l'élite de Bohême en début de règne, ainsi que l'intégration déjà plus avancée de la Bohême par rapport à la Hongrie dans l'ensemble monarchique, expliquent certainement que la couronne de Bohême apparaisse de manière secondaire dans les portraits de Marie-Thérèse. Il est en effet intéressant de citer de nouveau le portrait exposé à Bolzano, où Marie-Thérèse est représentée en roi de Hongrie en 1743 (P 29, Figure 17), année pourtant du couronnement de Bohême. Pour les élites d'une ville sans attaches particulières, ni avec la Hongrie, ni avec la Bohême, même à ce moment précis, le couronnement hongrois prime sur celui de Bohême. De même, il y a beaucoup moins de gravures reproduisant cet évènement qu'il n'y en a mettant en scène la cérémonie du couronnement hongrois sur la colline de Presbourg.

192 Lettre de Marie-Thérèse au comte Philipp Kinsky, citée d'après Arneth, Geschichte Maria Theresias, vol. 1, p. 414.

193 En marge du projet de couronnement, Marie-Thérèse rajoute la notice suivante: « Placet wie es bey der letzten Crönung ist gehalten worden "; voir Berning, Nach alltem löblichen Gebrauch, p. 180.

194 Berning, Nach alltem löblichen Gebrauch, p. 181.

195 Slavíček, «Schöne Sammlung », p. 136. 


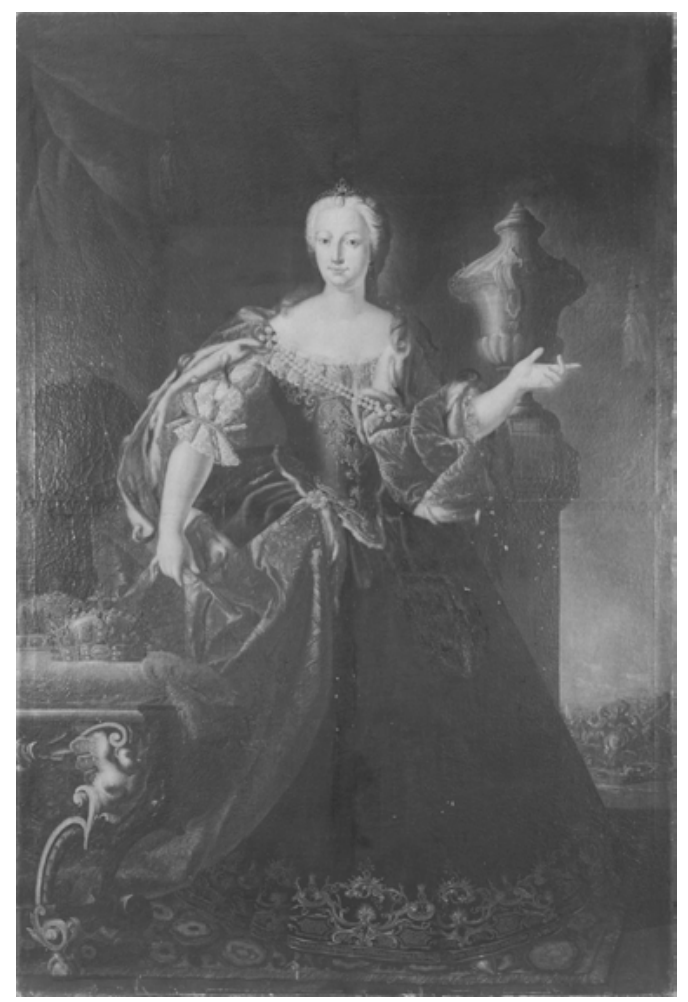

Figure 29: Atelier de Martin van Meytens, anonyme, Marie-Thérèse avec la couronne de Bohême, vers 1743, 230 x 151 cm, Galerie nationale de Prague, Inv. Nr. 0 462, République tchèque, Photographe (c) National Gallery Prague 2020.

Il est inédit en Bohême qu'une femme ne soit pas couronnée comme épouse du souverain mais comme souverain régnant ${ }^{196}$. Pour manifester cette différence, Marie-Thérèse n'est pas mentionnée dans les prières comme regina mais comme rex foemina, comme roi féminin ou femme-roi ${ }^{197}$. La remise de l'épée et l'adoubement sont d'autres éléments masculins du couronnement, réservés au roi et jamais conférés à son épouse : il s'agit de facto du couronnement d'un

196 Dans l'histoire de la Hongrie, il y avait au moins un précédent attesté avec Marie I ${ }^{\text {ère }}$, couronnée roi en 1382 ; voir Bak, « Roles and Functions of Queens », pp. 21-22 ; Süttő, « Der Dynastiewechsel Anjou-Luxemburg », pp. 79-80.

197 Berning, Nach alltem löblichen Gebrauch, pp. 181-182; Prokeš, « Marie Terezie », p. 349. 
roi. C'est ainsi que Marie-Thérèse prête serment en latin en se nommant « Ego Maria Theresia [. . . ] coronandus Rex Bohemiae ${ }^{198}$.

Tout au long de l'époque moderne, comme l'a montré Štěpán Vácha, le couronnement de Bohême forme un évènement important lors de la prise de légitimité et de souveraineté des Habsbourg. Déjà le couronnement de Ferdinand ${ }^{\text {er }}$ (en 1527) avait profondément marqué le sacre de Bohême. Le roi n'entre pas dans la cathédrale en vêtements royaux séculiers mais porte l'habit d'archiduc autrichien. Léopold $\mathrm{I}^{\mathrm{er}}$ entre par la suite dans la chapelle de Saint Wenceslas avec une couronne privée (une couronne appartenant à la famille et non aux états) sur la tête, habillé d'une robe royale attestant qu'il est déjà roi de Hongrie. Il reste vêtu de cette manière durant toute la cérémonie ${ }^{199}$. La couronne personnelle est ôtée de sa tête avant qu'il ne soit couronné avec la couronne de Saint Wenceslas. Par la suite, lors du couronnement de Charles VI en 1723, le souverain est déjà empereur romain et, de fait, roi de Bohême. Il arbore ainsi un chapeau muni d'une plume rouge " impériale », vêtu d'une longue cape de brocart rouge, le collier de l'Ordre de la Toison d'Or repose sur ses épaules. Dans la chapelle, Charles VI revêt la robe de couronnement. Il saisit à nouveau le collier tout en gardant sur la tête la couronne privée. Enfin, il enlève cette couronne privée et prête le serment royal qui précède l'onction et le couronnement ${ }^{200}$. Bien que Marie-Thérèse soit une femme, elle ne porte pas l'habit traditionnel, qui est l'habit de couronnement de l'épouse du roi durant cette période ${ }^{201}$. Comme pour le couronnement hongrois, elle est vêtue à la manière d'un véritable roi, dans la même robe de couronnement que son père Charles VI. La couronne de Saint Wenceslas, l'orbe, le sceptre ainsi que l'habit de couronnement de Bohême sont des éléments importants qui font partie des insignes de couronnement ${ }^{202}$. Ces insignes de couronnement deviennent des regalia sous Charles VI et sous Marie-Thérèse. Marie-Thérèse se fait ainsi représenter à deux reprises avec de tels insignes, manière de documenter ses droits et ceux de sa famille sur ces insignes nationaux qui deviennent des insignes dynastiques. Les Habsbourg tendent de plus en plus à se faire représenter de manière à souligner leurs revendications territoriales, souligne Vácha ${ }^{203}$.

198 « Moi Marie-Thérèse [. . . ] roi de Bohême à couronner »; cité d'après Berning, Nach alltem löblichen Gebrauch, p. 182.

199 Vácha, « 'Mutatio vestis' », pp. 254 et 258-259.

200 Vácha, «'Mutatio vestis' », pp. 259-262.

201 Vácha, " 'Mutatio vestis' », pp. 262 et 264.

202 Vácha, « Repräsentations- oder Krönungsornat », p. 229.

203 Vácha, « 'Mutatio vestis' », p. 264. 
Comme nous venons de le montrer, les couronnements sous Marie-Thérèse ont une grande valeur. Le couronnement de Bohême ne déroge pas à la règle ${ }^{204}$. Le portrait de Marie-Thérèse en habit de couronnement de Bohême commémore la cérémonie de 1743 et l'inscrit dans une continuité dynastique. C'est une attestation de la légitimité de la souveraine dans cette fonction de roi de Bohême bien que l'argument principal de continuité reste l'image de Marie-Thérèse en roi de Hongrie.

Puisque la plupart des portraits de Marie-Thérèse avec la couronne de Bohême apparaissent vers 1743, on peut penser qu'ils commémorent le couronnement de Marie-Thérèse en roi légitime de ce pays. On peut y lire aussi une certaine forme de propagande vis-à-vis des ordres et états de Bohême, afin de réaffirmer la présence impériale après l'intermède prussien qui n'a d'ailleurs pas laissé de bons souvenirs dans la population. Le titre de roi de Bohême est le plus haut que détiennent les Habsbourg à l'intérieur de l'Empire (la Hongrie, par exemple, ne fait pas partie de l'Empire), il est très important pour leur accès à l'élection impériale. Les insignes du pouvoir prennent une signification toute particulière sous le règne de Marie-Thérèse, toutes les couronnes sans exception sont l'objet d'un intérêt croissant de la part de la cour viennoise. Bien que la couronne de Hongrie occupe une place considérable et première par rapport aux autres insignes des pays de la Monarchie, la représentation d'autres insignes, notamment ceux de Bohême et d'Autriche, n'en est pas moins significative dans les portraits de Marie-Thérèse.

\section{d. Le chapeau archiducal}

Avec les couronnes de Hongrie et de Bohême, le chapeau archiducal autrichien occupe une place importante dans les portraits royaux. Il demeure néanmoins secondaire, par rapport à la couronne de Hongrie surtout, car il est moins représenté qu'elle. Lorsque le chapeau archiducal apparaît dans les portraits, il se trouve placé en arrière de la couronne de Saint Étienne, mais souvent à peu près à la même hauteur que la couronne de Bohême.

Lorsqu'au début du règne, Marie-Thérèse est peinte en archiduchesse d'Autriche, le chapeau archiducal est naturellement posé à ses côtés afin de signifier son rang. Dans ce type de portrait, le chapeau archiducal est alors le seul insigne représenté. La couronne de Hongrie ou la couronne de Bohême apparaissent parfois un peu derrière le chapeau archiducal. Comme tous les insignes de

204 Schwarzenberg, Die Sankt Wenzels-Krone, pp. 24-28 et Figure 27. 
pouvoir, le chapeau archiducal fait l'objet de soins particuliers, notamment en période de crise. Dans une situation militaire particulièrement menaçante, une lettre du 13 septembre 1741 contient l'ordre de Marie-Thérèse de ramener le chapeau archiducal à Vienne, dans la Schatzkammer, afin de le protéger ${ }^{205}$. Représenter les couronnes dans les portraits de Marie-Thérèse est ainsi une manière de réaffirmer un droit qui est réellement contesté. La dynastie conserve ses propres symboles d'unité comme la Hauskrone, la couronne de la Maison, ou l'Erzherzogshut, le chapeau archiducal, tels que nous pouvons les contempler dans les portraits de Marie-Thérèse ${ }^{206}$. Tout au long du règne, la couronne de Bohême et le chapeau archiducal sont presque systématiquement représentés en position secondaire, de retrait, à peu près au même niveau.

Sous Marie-Thérèse, la cour viennoise s’intéresse au chapeau archiducal. Dans les années 1740, on analyse et enquête sur le chapeau archiducal autrichien en écrivant des traités sur ce sujet ${ }^{207}$. La cour prend conscience de l'importance de ce symbole pour les pays héréditaires autrichiens. En effet, comme insigne du pouvoir séculier, le chapeau archiducal constitue un élément de référence majeure. Par la suite, à l'occasion du couronnement de Joseph II comme roi des Romains en 1764 , on réalise un nouveau chapeau archiducal ${ }^{208}$. L'archiviste de cour Theodor von Rosenthal, tout comme le chancelier d'État Kaunitz, reconnaissent en ce nouvel insigne la forme authentique du chapeau original ${ }^{209}$.

Revenons un peu plus en arrière. Dès 1358 ou 1359, le duc Habsbourg Rodolphe IV met en place dans sa chancellerie un ensemble de chartes en grande partie falsifiées, le Privilegium maius ${ }^{210}$, qui lui attribuent un certain nombre de droits et de privilèges exclusifs au sein de son empire, y compris le titre inédit « d'archiduc ». Un portrait, l'un des plus anciens de la peinture allemande, aujourd'hui au Dommuseum de Vienne, montre Rodolphe IV $^{211}$ avec le chapeau archiducal comme le décrit ce prétendu privilège. Ce tableau peut être interprété comme une revendication sur la dignité archiducale. Il faut à Rodolphe des insignes qui manifestent ses hautes prétentions. Tout comme la couronne

205 Ollinger, « Der Erzherzogshut, Zankapfel », pp. 63-66, 65.

206 Noflatscher, «'Staat' und 'Nation' », p. 172.

207 Telesko, Maria Theresia, pp. 94-95.

208 Telesko, Maria Theresia, p. 95.

209 Schütz, « Der österreichische Erzherzogshut », p. 61; Telesko, Maria Theresia, p. 95.

210 Lhotsky, Privilegium maius, pp. 16-26; Wolfinger, « Das Privilegium maius »; Schütz, «Der österreichische Erzherzogshut », p. 55.

211 Polleross, « Das frühneuzeitliche Bildnis als Quelle », p. 1011. 
familiale impériale, la Hauskrone, conçue plus tard, le chapeau archiducal est une invention de la famille Habsbourg ${ }^{212}$.

Ce chapeau archiducal est composé d'une coiffe de velours rouge, entourée de pointes. Recouvert de deux branches qui s'imbriquent, il est surmonté d'un grand saphir avec une croix, élément spirituel et visuel le plus important ${ }^{213}$. Le chapeau est fait avec une étoffe similaire à celle de l'habit et des coiffes des princes électeurs. En 1616, sur ordre de l'archiduc Maximilien III, ancien régent du Tyrol, un nouveau chapeau archiducal est fabriqué. On le conserve dès lors à l'abbaye de Klosterneuburg, il ne peut en être éloigné que lors des intronisations et des cérémonies d'hommage par les états autrichiens.

Le problème de la possession de la couronne s'applique tant au royaume de Hongrie que de Bohême ainsi qu'à la couronne impériale ou même au chapeau archiducal. À l'exception de la couronne impériale familiale, les couronnes sont en fait entre les mains des états. Même si le monarque tente de plus en plus de se les approprier, ces couronnes et insignes ne lui appartiennent pas en propre. Par l'intermédiaire des portraits et des insignes représentés dans les tableaux, Marie-Thérèse témoigne ainsi de son droit à détenir les symboles des pays.

Dans les Testaments Politiques de la souveraine de 1750 et 1755-1756, les états sont décrits, selon une vue assez réductrice, comme trop puissants, tandis que les princes ne sont que de faibles interlocuteurs des pays. Les états sont dominés par leurs intérêts personnels ${ }^{214}$, le prince en revanche est animé par le désir du bien commun. L'idée de bien commun, de gemeine Wohl, devient un principe supérieur, un élément clef du discours politique ${ }^{215}$. Le souverain est là pour unifier et rassembler les intérêts de chacun. Peut-on alors faire un lien entre cette idée de bien commun incarné par la souveraine et la diffusion, dans les années allant de 1745 à 1750, de portraits de Marie-Thérèse alors représentée avec quatre couronnes, celles de Hongrie et de Bohême, le chapeau archiducal et la couronne familiale, et tout particulièrement avec la couronne de Hongrie ou la couronne impériale familiale au premier plan ? Il serait tentant de répon-

212 Noflatscher, "'Staat' und 'Nation' », cet auteur a pu écrire que la Hauskrone et le chapeau archiducal étaient des contre-symboles d'unité pour la dynastie des Habsbourg, par rapport aux états, p. 172.

213 Schütz, «Der österreichische Erzherzogshut », p. 55, pp. 59-60.

214 Kallbrunner (éd.), Maria Theresias Politisches Testament, p. 93, cité par Cerman, « Opposition oder Kooperation », p. 382. Durant les négociations concernant le recès décennal, Haugwitz rend visite aux états de Bohême à Prague. Marie-Thérèse affirmera dans son Testament politique que son ministre était alors confronté à des ferme- und gescheiterten Köpfen, « des têtes fermées et ratées ".

215 Cerman, « Opposition oder Kooperation », pp. 376-377. 
dre que représentée au milieu de ses couronnes, la souveraine est in medio regni, au milieu du royaume.

Par la diffusion massive de ces portraits, Marie-Thérèse s'adresse à ses peuples en se laissant représenter avec leurs insignes respectifs. Chaque pays a sa place dans l'ensemble monarchique. En période de crise et de désunion, il est particulièrement important de représenter les insignes de chaque territoire auprès de Marie-Thérèse. Dans un contexte de déchirement, une représentation adaptée à chaque public, avec les insignes politiques des pays de la Monarchie, est nécessaire. Il s'agit de montrer que tous les pays ont leur place dans la Monarchie, derrière la figure de Marie-Thérèse, même si certains ont une place prioritaire par rapport à d'autres (du moins visuellement et symboliquement).

\section{e. L’habit pour remplacer la couronne dans certaines régions}

Dans certaines provinces comme les Pays-Bas autrichiens, où aucune couronne n'a de charge symbolique aussi forte qu'en Hongrie ou en Bohême, d'autres éléments de reconnaissance sont privilégiés. Le portrait à la robe de dentelle flamande réalisé par Martin van Meytens conservé à l'hôtel de ville de Gand ainsi que la copie réalisée pour l'hôtel de ville de Bruges, en sont de bons exemples.

Il n'est pas étonnant que Marie-Thérèse se fasse représenter en robe de dentelle, qu'elle ait même offert ce portrait à la ville de Gand (P 122) et que la ville de Bruges ( $\mathrm{P}$ 123, Figure 10), rivale de Gand, ait fait commander pour son propre hôtel de ville une réplique de ce motif qui symbolise une industrie vitale pour les villes flamandes, tout particulièrement au XVIII ${ }^{\mathrm{e}}$ siècle $^{216}$.

Les sujets se reconnaissent donc dans les portraits à travers la représentation des couronnes mais également dans le choix des habits qui mettent en scène Marie-Thérèse. Plus que les anciens états et ordres, ce sont davantage les pays considérés dans leur globalité sous l'angle des identités, que l'on pourrait qualifier de régionales, avec des insignes et des symboles bien reconnaissables, qui sont pris en compte dans la représentation royale. La représentation en robe de dentelle flamande est donc tout sauf anodine. Elle met en valeur un pays récemment acquis (en 1714) et qui avait été occupé par les troupes françaises dans les années 1740, durant la guerre de Succession d'Autriche. En raison de leur situation économique et financière, assez bonne, les Pays-Bas autrichiens sont en mesure d'apporter une grande aide financière à la Monarchie ${ }^{217}$.

216 Nous renvoyons ici à la discussion de ces circonstances au chapitre V.

217 Englebert, « Maria Theresia als Landesmutter der Niederlande », p. 114. 
Cela est d'autant plus vrai entre les années 1745 et 1750, dates d'apparition des portraits de Gand ( $P$ 122) et de Schönbrunn ( $P$ 121) où Marie-Thérèse est représentée avec cette robe ${ }^{218}$. La guerre qui s'est terminée en 1748 a en effet eu de lourdes conséquences financières pour la Monarchie.

La volonté de la souveraine de se faire représenter vêtue de cette robe est autant politique qu'économique. Il s'agit de mettre en avant cette province. Pour les états, lorsqu'ils font réaliser cette robe, il s'agit certainement de faire connaître les problèmes naissants d'une branche industrielle importante non seulement à Gand mais aussi à Bruges et à Bruxelles ${ }^{219}$. Les députés des états de Flandre décident dans ce contexte de faire réaliser une robe de dentelle. Par la suite, Marie-Thérèse se fait peindre en portrait avec cette robe. Deux portraits sont alors réalisés par Martin van Meytens. L'un se trouve dans la salle de cérémonie du château de Schönbrunn (P 121), le second est offert à la ville de Gand (P 122) pour la salle de réception de l'hôtel de ville, où il se trouve aujourd'hui encore.

Lorsque ce n'est pas l'habit, c'est la physionomie même de Marie-Thérèse qui semble adaptée au public local. Évoquons ainsi le portrait réalisé par le peintre brugeois Matthias de Visch pour l'hôtel de ville de Bruges en 1749. Ce portrait représente Marie-Thérèse d'une manière qui pourrait rappeler une patricienne flamande (P 124, Figure 11) ${ }^{220}$. Les traits et la robustesse de la souveraine sont plus accentués que dans les portraits viennois de Martin van Meytens. Les peintres locaux s'approprient l'image de Marie-Thérèse afin qu'elle convienne à leur public et que celui-ci puisse se reconnaître dans les portraits royaux.

Les différentes images de Marie-Thérèse donnent des indications sur les attentes et les revendications de la souveraine ainsi que sur celles des élites de chaque territoire de la Monarchie. Les couronnes sont les éléments qui unissent la Maison d'Autriche à ses pays, et les pays à la dynastie. Tant Marie-Thérèse que les états accordent une valeur politique et symbolique éminente à de tels insignes. La personne de Marie-Thérèse est l'élément commun qui lie toutes les images. En se faisant peindre avec les insignes des différentes provinces, en associant chacune à sa personne, la souveraine se fait le nœud et le lien qui réunit toutes ces relations dans un ensemble.

218 Barta, Familienporträts, pp. 7, 78 ; Duchesne, «Le souvenir », p. 182 ; Lisholm, Martin van Meytens, p. 100 ; Meulemeester, « Mathias de Visch », pp. 293-297; Yonan, Empress Maria Theresa, pp. 34-35. Rappelons également que des gravures relatant l'inauguration de Marie-Thérèse dans cette province ont été réalisées à cette époque, évoquons par exemple les gravures signées par Frans Pilsen à Gand, chez la veuve Pierre de Goesin, en 1744.

219 Merci à Klaas van Gelder d'avoir attiré notre attention sur ce point.

220 Meulemeester, « Mathias de Visch », pp. 299-302. 
Les modèles de représentation royale sont largement acceptés et propagés au sein des pays de la Monarchie, auprès des élites et des bâtiments représentatifs du pouvoir central. Diffusés à partir des différents territoires, bien qu'en grande partie issus de Vienne, les portraits concourent à refléter un ensemble étatique particulier. Les pays homogénéisent leurs représentations politiques et se signifient ainsi mutuellement qu'ils appartiennent à une même entité politique, grâce à la représentation de la souveraine et de ses couronnes.

\section{Le motif de la représentation impériale chez les Habsbourg et la couronne impériale familiale}

Marie-Thérèse parle toujours de Mein Haus ${ }^{221}$, soulignant ainsi le rôle fédérateur et structurant de la Maison d'Autriche dans la politique des Habsbourg. La dignité impériale ne suffit pas à unifier tous les pays car une grande partie de la Monarchie ne fait pas partie de l'Empire, néanmoins un grand enjeu du règne reste de reconquérir la dignité impériale dont l'importance symbolique demeure cruciale.

Les grands souverains de l'époque moderne ont aspiré à acquérir ce titre impérial, hérité des empereurs Romains. En raison de l'éloignement progressif entre les États héréditaires des Habsbourg et le Saint Empire, le royaume de Hongrie offre potentiellement une autre légitimité très utile dans la situation de Marie-Thérèse. Marie-Thérèse, en tant que femme, ne peut être élue empereur, cependant elle reste et demeure le souverain, en position de supériorité par rapport à son époux l'empereur.

La dignité impériale n'a-t-elle plus d'importance pour autant ? N'existe-t-il pas un insigne, une couronne, qui pourrait relier tous ces pays et signifier l'appartenance à la Monarchie?

\section{a. La couronne du Saint Empire}

L'élément impérial est un aspect très important déjà mis en valeur et souligné par les Habsbourg tout au long de l'époque moderne. L'expression et l'idée d'Austria Sacra sont alors analogues à celle de Sacrum Imperium ${ }^{222}$. La représentation de la Maison d'Autriche au cours du XVII ${ }^{\mathrm{e}}$ et $\mathrm{du} \mathrm{XVIII}^{\mathrm{e}}$ siècle repose

221 Klingenstein, « Was bedeuten 'Österreich' und ‘österreichisch’? » p. 171.

222 Matsche, Die Kunst im Dienst der Staatsidee, vol. 1, p. 78. 
en bien des aspects sur l'opposition et la rivalité avec le roi de France Louis XIV qui, lui aussi, entretient des revendications sur la couronne impériale. À la différence du culte de la personnalité voué à Louis XIV, il est primordial pour les Habsbourg de souligner la tradition familiale et de légitimer leur pouvoir impérial en démontrant et en insistant sur la continuité du lien de génération en génération entre la Maison d'Autriche et l'Empire ${ }^{223}$.

Le père de Marie-Thérèse, Charles VI, se montre volontiers de manière somptueuse notamment dans sa représentation en tant qu'imperator. Cette mise en scène équestre est liée à la souveraineté des Habsbourg comme empereurs du Saint Empire romain germanique, cette translatio imperii au travers de laquelle les Habsbourg apparaissent comme les successeurs légitimes des «Césars » Romains ${ }^{224}$. Les monuments sacrés symbolisent également l'idée d'empire et la légitimation de la souveraineté habsbourgeoise $\mathrm{e}^{225}$. Par le Privilegium maius, forgé par Rodolphe IV en 1359 et validé par les confirmations des empereurs Habsbourg depuis Frédéric III en $1453^{226}$, l'archiduché d'Autriche jouit d'une place particulière au sein de l'Empire. Notons aussi que ce privilège est une nouvelle fois confirmé par Charles VI en $1729^{227}$. Quant à la couronne impériale, elle est dans la famille depuis 1438 sous Albert II. Sur certains cadres qui entourent les portraits de Marie-Thérèse figure le Doppeladler, l'aigle impérial à deux têtes. Citons l'exemple du double portrait de Marie-Thérèse et de François Étienne à l'abbaye de Sankt Florian, entouré d'un cadre arborant l'aigle impérial et le collier de la Toison d'Or.

Les portraits représentant la souveraine au côté de la couronne impériale de Nuremberg sont relativement rares dans notre corpus même s'ils ne sont pas totalement absents. Désormais la couronne impériale familiale (également désignée sous le terme de Hauskrone, Mitrakrone ou de Rudolfskrone) incarne la dignité impériale dans les portraits de Marie-Thérèse, tandis que son époux est peint avec la véritable couronne impériale.

Revenons un peu plus précisément à la description des couronnes. La couronne impériale de Nuremberg présente une forme unique. Elle a probablement été créée pour le couronnement d’Otton le Grand en 962. Constituée de

223 Polleross, « Zur Repräsentation der Habsburger », p. 92.

224 Matsche, « Die Verherrlichung der kaiserlichen Majestät », p. 383; voir plus généralement Matsche, Die Kunst im Dienst der Staatsidee, vol. 1, pp. 291-332, notamment p. 291.

225 Lorenz, « Der habsburgische 'Reichsstil' », p. 166. Lorenz évoque notamment la Pietas Austriaca comme une idée de l'Empire et de la légitimité de la souveraineté Habsbourg.

226 Luger, « Daz . . . unser gedechtnuss », pp. 245-250.

227 Lhotsky, Privilegium maius, p. 37; Winkelbauer, « Die Bedeutung des Privilegium maius », p. 331. 
huit plaques, chiffre impérial, chiffre de la perfection, des pierres précieuses et des perles ornent ses plaques, douze pierres précieuses se trouvent au centre, douze comme les douze tribus d'Israël. Quatre plaques montrent des figures provenant de l'Ancien Testament. L'arc de la couronne est surmonté d'une croix, symbole de la souveraineté au nom du Christ ${ }^{228}$. Aujourd'hui conservée à Vienne, la couronne du Saint Empire était depuis 1424 à Nuremberg et n'était utilisée que pour les couronnements.

En tant que femme, Marie-Thérèse ne peut prétendre à la dignité impériale, toutefois en tant qu'épouse d'empereur, elle est de fait impératrice. Cette situation complexe est également liée à l'autre point délicat pour Marie-Thérèse, celui de faire reconnaître l'empereur issu de la maison de Lorraine. La continuité dynastique reflétée dans les portraits comme dans d'autres types de supports renvoie à une très ancienne ambition des Habsbourg, transformer le titre impérial électif en titre héréditaire, si ce n'est en nouvel empire, qui serait de plus en plus détaché du Saint Empire pour devenir proprement habsbourgeois.

Le portrait de Marie-Thérèse comme roi de Hongrie et de Bohême et celui de François Étienne comme empereur du Saint Empire entraînent quasisystématiquement un doublement du nombre de portraits de la famille impériale après $1745^{229}$. Traditionnellement, les empereurs Habsbourg se laissaient représenter aux côtés de leurs épouses impératrices, mais ici, la situation, inversée, crée une urgence. Il était possible auparavant de mettre un portrait de l'impératrice à côté de celui de l'empereur. Après 1745, cela devient nécessaire. Il s'agit de montrer le représentant des titres héréditaires ainsi que le détenteur de la dignité impériale, côte à côte. Marie-Thérèse est à la fois épouse et souveraine.

La Monarchie a atteint un de ses objectifs de reconnaissance après l'élection et le couronnement de François Étienne de Lorraine comme empereur en 1745. La réunion des titres n'est pas sans susciter quelques difficultés : il est alors nécessaire de trouver une solution pour représenter leur répartition entre mari et femme sans créer d'inégalité. La Monarchie est toujours liée à la dignité impériale comme en témoigne l'abondante production, entre 1745 et 1765, de portraits de Marie-Thérèse avec des portraits de son époux, deux faces complémentaires. La répartition des titres est séparée visuellement entre Marie-Thérèse et son époux, puis entre elle et son fils Joseph en fin du règne.

228 Haag, Kaiserliche Schatzkammer, pp. 22-25.

229 Lisholm, Martin van Meytens, p. 135: «Im Jahre 1745 wurde Franz I zum Kaiser gekrönt und die Produktion hat stark zugenommen ». 
Après 1745 et le couronnement tant attendu de François Étienne, qui est, d'une certaine façon, le propre succès de Marie-Thérèse ${ }^{230}$, il est nécessaire de représenter François Étienne comme empereur avec la couronne impériale de Nuremberg. L'archiduchesse d'Autriche, également roi de Hongrie et de Bohême est, quant à elle, peinte avec les couronnes de ces pays ainsi qu'avec la couronne impériale familiale ${ }^{231}$. Ce modèle binaire est très fréquent jusqu'en 1765, année de la mort de François Étienne. Puis, à partir de cette date et jusqu'à la mort de la souveraine en 1780 , la reine majestueuse cède la place à la représentation de la Kaiserin Witwe, la veuve impératrice accompagnée de son corégent et héritier, l'archiduc Joseph devenu l'empereur Joseph II.

En position d'épouse dans les portraits de la période 1745-1765, MarieThérèse ne s'appuie pas toujours sur le sceptre mais laisse la place à l'empereur qui accède alors à une position de monarque régnant. Il est alors plus approprié de représenter l'empereur en position première de " chef ». Dans ce cas, les mains de Marie-Thérèse ne tiennent plus aucun insigne du pouvoir. Dès 1745 , le problème à résoudre pour la représentation artistique de couple devient en effet très délicat. Les titres sont partagés, François Étienne n'en possède qu'un seul mais qui reste toujours le plus éminent : la dignité impériale ${ }^{232}$. Il s'agit d'éviter de créer l'impression d'une subordination de Marie-Thérèse à François Étienne, ou l'impression que les titres de Marie-Thérèse passent sous le contrôle de François Étienne. La solution est la représentation complémentaire du couple sur deux tableaux séparés la plupart du temps, l'empereur et le monarque

230 Sur ce sujet de la répartition des titres entre Marie-Thérèse et François Étienne de Lorraine, voir notamment l'article de Bettina Braun, qui propose l'inscription sur le double sarcophage du couple impérial comme exemple de la position particulière de Marie-Thérèse comme impératrice : Rom. Imperii Maiestatem Domui Suae Restituit, ce qui signifie que Marie-Thérèse est celle qui a rendu la dignité impériale à sa Maison. L'auteur insiste également sur le fait que sur le sarcophage, les deux époux sont tournés l'un vers l'autre, tenant ensemble le sceptre du couronnement hongrois, voir Braun, « Maria Theresia », p. 227.

231 La souveraine, comme roi de Hongrie et de Bohême, était une tête couronnée. Un problème de préséance concernant le cérémoniel était bel et bien réel entre elle et son mari, même avant le couronnement de celui-ci comme empereur ; voir Stollberg-Rilinger, Maria Theresia, pp. 69-70 ; voir aussi sur cette question Braun, « Maria Theresia », p. 216 et pp. 218-219, l'auteur insiste sur le fait que sur les pièces de monnaie la souveraine est aussi peinte comme impératrice, et qu'elle laisse à partir de 1746 aussi la place à l'image de François Étienne, et après 1766 à l'image de Joseph et de l'empereur défunt.

232 Dans son ouvrage consacré à Marie-Thérèse, Braun explique que beaucoup d'impératrices de l'époque moderne n'ont pas été couronnées ; voir Braun, Eine Kaiserin und zwei Kaiser, pp. 82-83 ; et encore Fühner, « Kaiserinnenkrönungen », p. 294. Ce qui était nouveau dans le cas de Marie-Thérèse et de François Étienne était le fait que l'empereur devait sa position à sa femme. 
des territoires héréditaires, ou sur deux plans d'un même tableau pour les quelques doubles portraits que nous possédons.

Le fait que Marie-Thérèse refuse de se laisser couronner en tant qu'impératrice, en tant qu'épouse de l'empereur en 1745, et ce à la grande déception de son époux, joue un rôle important d'un point de vue symbolique et politique ${ }^{233}$. La souveraine conserve ainsi son indépendance, marque sa différence par rapport aux autres impératrices, et souligne aussi la position des pays héréditaires en tant qu'unité différente, si ce n'est supérieure et bien distincte de l'Empire $^{234}$. Marie-Thérèse n'est ni empereur ni impératrice du Saint Empire :

Tout ce que je puis en deviner au risque de me tromper, c'est que peut-être Elle regarde ce couronnement au-dessous des deux Couronnes Masculines qu'Elle porte, ayant une fois dit qu'en fait de couronner Elle ne vouloit plus changer de sexe $\mathrm{e}^{235}$ et m'ayant répété aujourd'huy que ce couronnement n'étoit qu'une comédie, et qu'Elle ne vouloit pas la jouer $^{236}$.

Il existe une certaine tension, si ce n'est une forme d'antagonisme pour les Habsbourg, entre leur rôle d'empereurs et leurs devoirs en tant que souverains des pays héréditaires ${ }^{237}$.

Ainsi devant l'impossibilité d'élire et de couronner Marie-Thérèse en tant qu'empereur, des solutions artistiques sont proposées - par les portraits de François et de Joseph aux côtés de ceux de Marie-Thérèse. La couronne impériale familiale est souvent peinte dans les portraits de Marie-Thérèse tandis qu'à partir de cette période, son époux puis son fils, sont systématiquement re-

233 Whaley, « Die Habsburgermonarchie », p. 295.

234 Voir notamment Whaley, "Die Habsburgermonarchie », p. 295; Yonan, Empress Maria Theresa, p. 30.

235 C'est-à-dire qu'ayant été « homme » lors de ses couronnements de Hongrie et de Bohême, elle ne souhaite plus redevenir " femme » pour être couronnée à Francfort.

236 Lettre du chancelier d'Etat, Anton Corfiz comte Ulfeld, à François Etienne, datée du 22 août 1745, citée d'après Arneth, Geschichte Maria Theresias, vol. 3, p. 429. Voir aussi les propos de Regina Schulte à ce sujet, Der Körper der Königin ou The Body of the Queen, pp. 18-20, Regina Schulte souligne le fait que Marie-Thérèse rechigne à participer à la cérémonie de couronnement de son époux à Francfort, qu'elle refuse de se laisser couronner comme impératrice car elle porte déjà deux couronnes masculines, dont elle ne souhaite pas rabaisser le prestige en se faisant couronner comme impératrice, comme épouse de l'empereur. Toutefois, MarieThérèse parvient à transformer la journée de couronnement de son époux en une procession triomphale à son égard. Et Regina Schulte de rajouter que Marie-Thérèse était devenue mâ̂tresse « dans l'art de jouer sur la transgression entre son corps politique et son corps naturel », voir p. 20.

237 Whaley, «Die Habsburgermonarchie », p. 313. Whaley rajoute également que ces deux fonctions étaient complémentaires pour le rôle des Habsbourg en Europe. 
présentés avec la couronne impériale conservée à Nuremberg, et qui n’appartient pas en propre aux Habsbourg. Plus rarement, l'empereur et son épouse, sont peints ensemble comme dans le double portrait de l'abbaye de Sankt Florian.

Dans quelques portraits, cependant, Marie-Thérèse est peinte seule à côté de la véritable couronne impériale, couronne qu'elle ne peut, en principe, porter, car elle n'est pas couronnée impératrice ${ }^{238}$. Ces portraits ne sont pas les plus répandus mais sont toutefois réalisés, pour certains d'entre eux, par de grands peintres de cour. Ce sont parfois des commandes de la cour, en particulier les deux portraits de Marie-Thérèse en habit de couronnement de Bohême, avec la couronne de Saint Wenceslas sur la tête.

Ainsi au Bundeskanzleramt (la chancellerie fédérale) de Vienne (P 74), le portrait de Marie-Thérèse en roi de Bohême fait allusion au droit de celui-ci de participer à l'élection de l'empereur (couronne de Saint Wenceslas sur la tête, à côté d'elle sont posées sur une table la couronne de Hongrie, le chapeau archiducal et la couronne impériale). Il peut aussi s'agir de la revendication du titre impérial pour sa famille contre le prétendant bavarois Charles VII (ou Charles Albert de Bavière). En plus de s'être fait couronner en tant qu'empereur du Saint Empire, celui-ci s'était fait sacrer roi de Bohême à Prague en 1743, durant une assez courte occupation de la ville par ses forces. Ce sacre avait même été une condition préalable à son élection impériale. Il se peut que la souveraine souhaite montrer qu'après avoir repris la couronne de Bohême, elle reprendra aussi celle de l'Empire à l'usurpateur.

En 1772, afin d'aménager la résidence impériale rénovée de Prague, MarieThérèse se fait de nouveau représenter en habit de couronnement de Bohême, par le peintre de cour Auerbach sceptre en main, avec la couronne de Bohême sur la tête et à côté de la seule couronne impériale (P 76, Figure 30) ; ce portrait ressemble beaucoup au tableau exécuté en 1743 par l'atelier de Meytens (P 74) ${ }^{239}$. Cette couronne impériale est donc principalement liée à un public issu de Bohême et rappelle le lien très fort entre la Bohême et le Saint Empire. En 1743 comme dans les années 1770, il est nécessaire de rappeler ce lien.

Les ateliers de Meytens et d'Auerbach, artistes de cour, ont ainsi peint par deux fois au moins Marie-Thérèse en habit de couronnement de Bohême à côté de la couronne impériale. L'appartenance de la Bohême à l'Empire se réduit plus ou moins à la dignité électorale et l'électorat est une voie d'accès à l'élec-

238 Braun, « Maria Theresia », p. 226, comme Braun l'affirme, Marie-Thérèse était certainement plus Landesherrin que Kaisergattin.

239 Vlček, « Die Burg », pp. 90-91. 
tion impériale. Plus encore, la Bohême est un électorat de l'Empire, le seul que possèdent les Habsbourg (l'Autriche n'a jamais été un électorat). La possession de la Bohême donne ainsi aux Habsbourg la possibilité de se faire représenter à côté de la couronne impériale dans leurs portraits en habit de couronnement de Bohême.

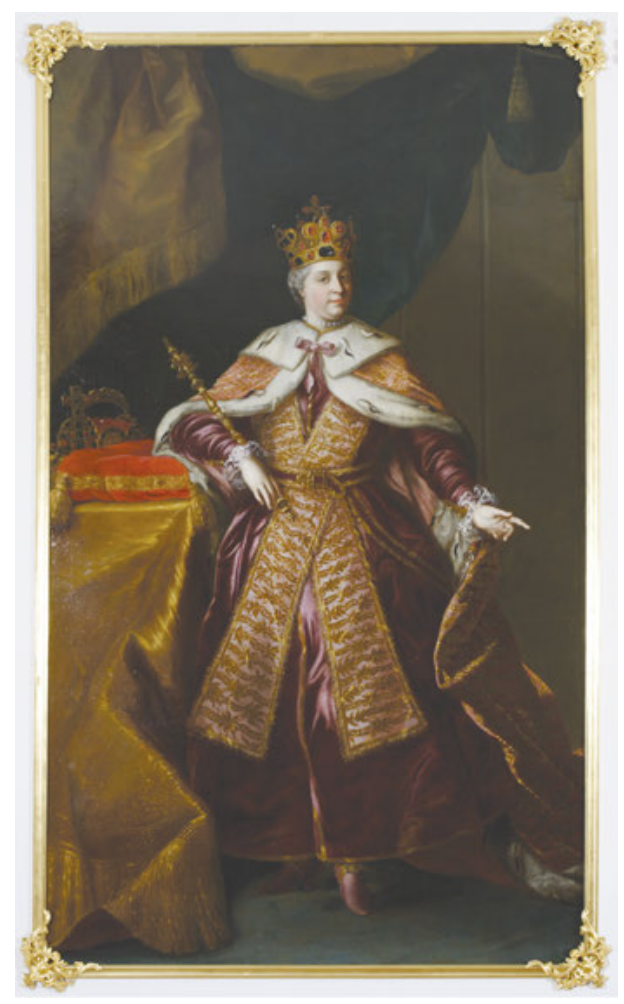

Figure 30: Johann Karl Auerbach, Marie-Thérèse en habit de couronnement de Bohême, 1772 , 225 x 150 cm, Inv. Nr. HS 83, Prague Castle Art Collections, République tchèque.

Un autre portrait de Marie-Thérèse, représentée de moitié à côté de la couronne impériale, probablement peint dans les années 1750, sert à décorer la résidence de l'archevêque d'Olomouc ( $\mathrm{P}$ 57). Le Musée de la ville de Prague possède également un portrait de Marie-Thérèse peinte avec l'insigne impérial au côté de l'archiduc Joseph enfant (P 78, Figure 31). Il s'agit à Olomouc, comme à Prague, de l'œuvre d'artistes locaux de Bohême. Certains artistes régionaux de Bohême représentent Marie-Thérèse comme une impératrice, différente toutefois de ses parentes étant donné sa situation, selon un modèle répandu de l'impératrice à 
côté de la couronne impériale. En tant que femme de l'empereur, Marie-Thérèse est de fait impératrice, et surtout la mère du futur roi des Romains. En représentant Marie-Thérèse avec la couronne impériale ${ }^{240}$, on se rapproche d'une iconographie traditionnelle des impératrices.

Les peintres offrent aussi l'image de la mère à côté de son enfant et des titres impériaux que sera un jour appelé à porter cet héritier. Ce modèle ne concernait toutefois pas Charles VI ni Joseph I, faute d'héritiers, mais dans la situation de Marie-Thérèse, il s'agit d'un argument de poids. C'est en particulier le cas dans les portraits montrant Marie-Thérèse et Joseph enfant, tous deux proches de la couronne impériale. Outre celui du Musée de la ville de Prague ( $P$ 78, Figure 31), un autre portrait associant Joseph, Marie-Thérèse et la couronne impériale, se trouve à l'abbaye de Seitenstetten en Autriche (P 80, Figure 33). Dans les deux tableaux conservés dans cette abbaye et au Musée de la ville de Prague, trois éléments essentiels, Marie-Thérèse, la couronne impériale et l'archiduc Joseph, vêtu en Hussard hongrois avec l'Ordre de la Toison d'Or, sont peints au sein d'un même espace, à la même hauteur même dans le portrait de Prague, mettant en valeur la continuité entre les Habsbourg-Lorraine et la dignité impériale. La dignité impériale ne semble ainsi être interrompue ni par la montée sur le trône d'une femme ni par la fondation d'une nouvelle dynastie. $\mathrm{Au}$ contraire, le fils de Marie-Thérèse, premier empereur de la dynastie des Habsbourg-Lorraine, est bien l'héritier du Saint Empire, le futur roi des Romains. Cette mise en scène souligne que même si la souveraine, en tant que femme, ne peut prétendre pour elle au plus haut titre (la dignité impériale), elle n'en reste pas moins l'épouse de l'empereur comme la mère du futur empereur et la fondatrice de la nouvelle dynastie des Habsbourg-Lorraine qui conserve toujours ses droits à la dignité impériale. Bien qu'une femme monte sur le trône et qu'une nouvelle dynastie soit fondée, une forme de continuité dans la rupture est ainsi assurée. La dignité impériale, encore représentée, est directement associée à la nouvelle dynastie des Habsbourg-Lorraine.

Les portraits représentant Marie-Thérèse avec la couronne impériale et comme mère du futur roi des Romains semblent souvent des commandes locales, faites à l'occasion notamment du couronnement de François Étienne, ou dans l'attente de ce couronnement comme empereur du Saint Empire romain germanique.

Conservé au Musée de la ville de Prague, ce portrait ci-dessous a peut-être été réalisé par un artiste tchèque, dans l'entourage du cercle d'Auerbach, vers 1745, du moins après 1741. La souveraine est peinte avec Joseph enfant, vêtu de

240 Kostelnickova, « 68. Portrait of Empress Maria Theresa », pp. 110-111. Voir la description d'un portrait de la souveraine avec la seule couronne impériale. 


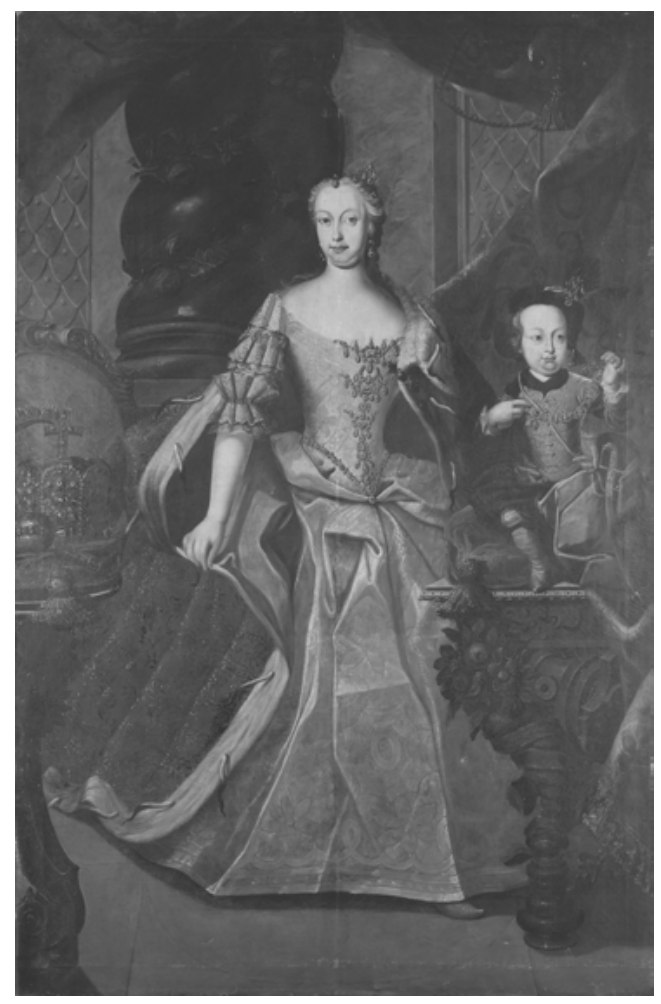

Figure 31: Cercle d'Auerbach, Marie-Thérèse et Joseph enfant, vers 1745, 231,5 x 150,5 cm, Musée de la ville de Prague, Inv. Nr. H 029 503, Prague, République tchèque. Collections du Musée. The City of Prague Museum.

l'habit de Hussard et arborant l'Ordre de la Toison d'Or. La couronne impériale est représentée à côté d'eux.

En 1745, François Étienne est élu et couronné empereur du Saint Empire romain germanique. Déjà couronnée comme roi de Hongrie et de Bohême en 1741 et 1743, Marie-Thérèse est représentée la main en direction des couronnes ou tendue délicatement vers les insignes du pouvoir. Si Marie-Thérèse reste toute sa vie le souverain, elle est aussi en position d'épouse par rapport à l'empereur, qui lui est désormais peint vêtu du manteau espagnol, le costume traditionnel de cour, représenté à côté de la couronne impériale et parfois appuyé sur un sceptre.

Dans certains doubles portraits de Marie-Thérèse et de son époux, on voit l'empereur François $I^{\text {er }}$ tenir le sceptre tandis que la main de sa femme relève délicatement le manteau royal. L'absence de gestes d'appropriation du pouvoir 
est en elle-même significative et peut souvent être expliquée par l'usage auquel un portrait était destiné. Dans ces portraits précisément, Marie-Thérèse apparaît en position d'épouse, bien que toujours souveraine des territoires héréditaires, tandis que François Étienne est représenté avec une gestuelle de souverain. À l'époque de son couronnement comme empereur du Saint Empire en 1745, et lorsque les tableaux sont exposés dans des Kaiserzimmer, salles dédiées à l'empereur plus qu'à la souveraine des pays héréditaires, il est important de symboliser sa position par ce type de posture, donnant de fait à Marie-Thérèse son rôle d'épouse et rappelant le partage des titres. C'est le cas notamment au château de Bruchsal (P 88, Figure 21), dans la résidence des princes-évêques de Spire, où la salle de marbre, ou Kaisersaal, expose le portrait de François Étienne appuyé sur le sceptre à côté de la couronne impériale. Dans un autre portrait près de lui, Marie-Thérèse est représentée avec les couronnes mais ne s'appuie pas sur le sceptre. Dans ces espaces ecclésiastiques du Saint Empire, comme au château de Bruchsal, c'est la figure de l'empereur qui est traditionnellement mise en valeur. Afin d'assurer la bonne répartition des rôles entre les membres du couple, c'est l'empereur qu'il faut aussi légitimer et donc représenter de manière régnante.

Un modèle de portrait, apparu aux alentours de 1745, lors du couronnement de François Étienne comme empereur du Saint Empire romain germanique, représente Marie-Thérèse en robe de soie bleue tandis que son époux est en position d'empereur. Ce modèle, diffusé en de nombreux exemplaires, présentent diverses variations dans la position des mains. C'est ainsi qu'un des modèles exposés au Musée Brukenthal de Sibiu, ancienne région de Transylvanie (P 90), représente Marie-Thérèse avec la main gauche posée sur la couronne impériale familiale, la main droite relevant le manteau, tandis qu'un portrait similaire conservé à l'abbaye de Göttweig en Autriche (P 96) montre MarieThérèse la main droite relevant son manteau et la main gauche tendue, ouverte, vers le vide, et non posée sur la couronne. Les répliques et copies similaires, qui se trouvent chez les princes évêques à Bruchsal (P 88, Figure 21) mais aussi à Augsbourg (P 105) ainsi qu'au Musée national germanique de Nuremberg (P 89), anciennes collections des Seckendorff, ou encore à l'abbaye de Pannonhalma en Hongrie ( $\mathrm{P}$ 86), proposent des portraits avec une position similaire de la main légèrement tendue vers le manteau royal, ou le relevant. Les visages et les corps des deux souverains sont alors légèrement tournés l'un vers l'autre. En outre, souvent un seul des membres du couple s'appuie sur le bâton de commandement, c'est parfois François Étienne tandis que Marie-Thérèse pose la main sur la couronne ou se contente de relever délicatement son manteau (comme dans les portraits de Bruchsal, Nuremberg, Augsbourg et de Pannonhalma). La situation peut tout aussi bien être inversée, c'est alors Marie-Thérèse qui est représentée proche de son époux, avec le bâton en main, à moins que les 
deux membres du couple n'aient le bâton en main comme à Eggenberg (P 136). Il s'agit tantôt de représenter le couple impérial, l'époux, François Étienne avec son épouse Marie-Thérèse, tant de créer une sorte d'équilibre dans le couple. Dans d'autres tableaux, comme dans le double portrait de Sankt Florian (P 135, Figure 32), il est plutôt question de mettre en scène la souveraine des pays héréditaires à côté de son corégent qui la seconde, en assumant notamment la dignité impériale.

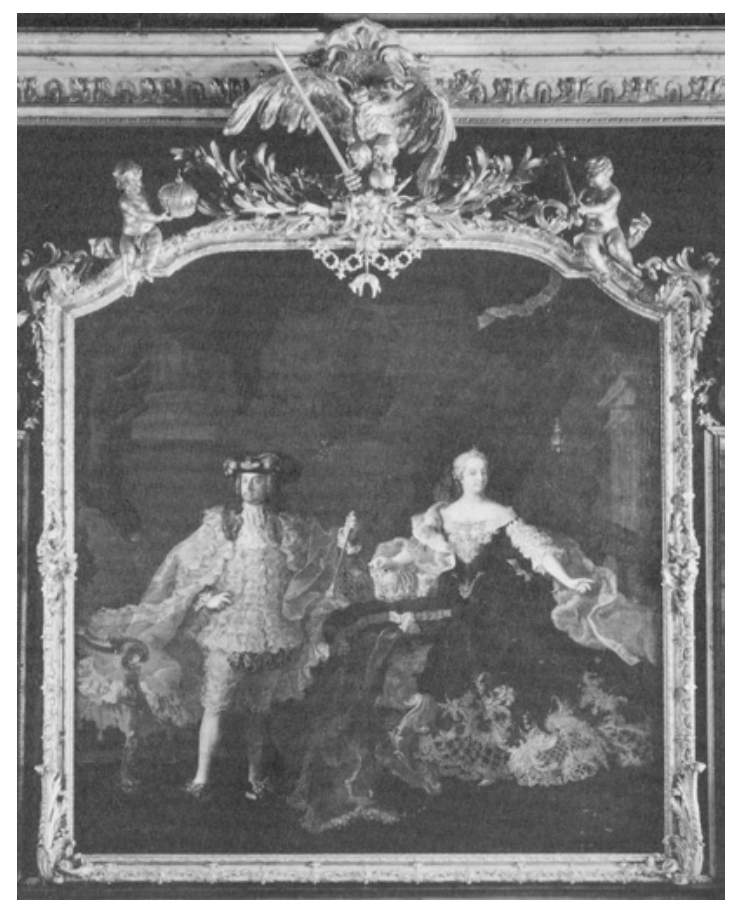

Figure 32: Peter Kobler, double portrait de Marie-Thérèse et de François I ${ }^{\mathrm{er}}, 1746$, "Stiftsbibliothek St. Florian », 320 x 300 cm, Inv. Nr. 76/12, Sankt Florian, Augustiner Chorherrenstift, Autriche.

Dans ce double portrait de Peter Kobler conservé à l'abbaye de Sankt Florian ${ }^{241}$, la souveraine est représentée à la gauche de son époux qui, lui, s'appuie sur le sceptre dans une position souveraine (P 135, Figure 32). Dans la salle impériale

241 Sur le double portrait en particulier de Peter Kobler, voir Yonan, Empress Maria Theresa, p. 31 et Hertel, Banakas, « Die Gestik Maria Theresias », p. 209. 
où ce double portrait est conservé, l'empereur François $\mathrm{I}^{\mathrm{er}}$ apparaît en manteau espagnol, sceptre en main, comme empereur. Marie-Thérèse, elle, est représentée, légèrement en retrait par rapport à François Étienne ${ }^{242}$, sa main gauche tendue gracieusement vers sa robe et vers le côté, sa main droite vers les couronnes. La complémentarité entre la dignité impériale de François Étienne et la souveraineté héréditaire de Marie-Thérèse est bien visible.

Comme la figure de l'empereur régnant, sceptre en main, la figure d'autorité de Marie-Thérèse côtoie parfois, bien que rarement, celle du roi guerrier. Ces deux facettes du pouvoir se retrouvent dans des espaces ecclésiastiques, comme à l'abbaye de Melk où les deux portraits de Marie-Thérèse (P 21) et de François Étienne, réalisés par l'atelier de Martin van Meytens vers 1741, sont exposés près de l'escalier qui conduit aux chambres impériales. De tels portraits où François Étienne est représenté en armure, se trouvent aussi dans l'abbaye de Lilienfeld en Basse-Autriche (en pendant au portrait de Marie-Thérèse, $\mathrm{P}$ 67, Figure 4), au château d'Eggenberg près de Graz (le portrait équivalent de MarieThérèse est le $\mathrm{P}$ 136), et dans la résidence épiscopale, puis archiépiscopale, d'Olomouc en Moravie (en pendant au portrait de Marie-Thérèse $P$ 56).

«On ne peut pas non plus comprendre l'histoire autrichienne sans la position impériale dans l'Empire ${ }^{243}$. Roi de Hongrie, Marie-Thérèse se désigne et est désignée en effet comme Kaiserlich-Königliche Majestät, von Gottes Gnaden Römische Kaiserin ${ }^{244}$. Peu après la difficile élection de François Étienne à la tête du Saint Empire, la signification et l'importance de la couronne impériale pour les Habsbourg est objet de débat dès $1746^{245}$. L'opinion retenue est celle du vice-chancelier impérial Rudolf Joseph comte Colloredo-Waldsee ${ }^{246}$, qui souligne

242 Mentionnons les propos de Barbara Stollberg-Rilinger qui évoque le fait qu'en tant que roi de Bohême et archiduchesse d'Autriche, la souveraine était la vassale de son époux l'empereur, même si la manifestation de ce lien par le rituel d'un hommage à genoux fut évitée ; voir Stollberg-Rilinger, Maria Theresia, pp. 163-164.

243 Press, «Österreichische Großmachtbildung », p. 154.

244 De telles désignations sont couramment employées dans des ouvrages contemporains à l'époque de Marie-Thérèse, tel celui de Drönner Heinrich Ludwig, « Ihrer Kaiserlich Königlich Apostolischen Majestät Vorstellung und ersuchen an ihre hohe Mitstände des deutschen Reichs gegen die widerrechtlichen und friedsbrüchigen Handlungen seiner könig-Preussisch Majestät bei Gelegenheit der bayerischen Erbfolge », Francfort, 1778.

245 Braun, « Maria Theresia », pp. 214-217. Bettina Bran évoque le rôle de François Étienne comme empereur.

246 Colloredo-Waldsee fut vice-chancelier impérial (Reichsvizekanzler) de 1740 à 1742 puis de 1745 à 1788; voir Gnant, " Franz Stephan von Lothringen als Kaiser », p. 126; Hochedlinger, « Die Reichshofkanzlei », pp. 328-329; Stollberg-Rilinger, Maria Theresia, pp. 164-165. 
que l'Empire ne peut pas fonctionner sans les Habsbourg ${ }^{247}$. Mais de même, insiste-t-il, la dynastie serait affaiblie sans le soutien de l'Empire ${ }^{248}$. Juste après son accession à la dignité impériale, en novembre 1766, Joseph II soumet à son tour une série de questions concernant le potentiel de l'Empire au conseiller d'État Johann Anton comte Pergen, à Colloredo, toujours en fonction, ainsi qu'au chancelier d'État Kaunitz ${ }^{249}$. Toutes les réponses obtenues par Joseph soulignent de nouveau la grande valeur de la dignité impériale, en particulier pour la Maison d'Autriche ${ }^{250}$. La couronne impériale procure à celle-ci une position prioritaire par rapport aux autres Maisons princières européennes ainsi qu'une série d'alliés potentiels en temps de guerre ${ }^{251}$.

Rappelons que François $\mathrm{I}^{\mathrm{er}}$ de Lorraine est le seul empereur du XVIII ${ }^{\mathrm{e}}$ siècle qui parvient de son vivant à faire élire son fils, le futur Joseph II, en tant que roi des Romains en $1764^{252}$. Cela a lieu après de nombreuses difficultés et de subtiles négociations ${ }^{253}$. Dans des commandes de cour et des commandes locales, la continuité de la dignité impériale entre les Habsbourg et les Habsbourg-Lorraine est manifestée et représentée par la couronne impériale. Entre les deux dynasties, aucune rupture majeure ne doit apparaître.

Si l'Empire continue à conserver une importance pour la Monarchie, la définition donnée à cette entité évolue.

« Par mon Autriche, j'entends [. . .] tous les royaumes et pays héréditaires de la Maison d'Autriche germanique, qu'ils se trouvent à l'intérieur ou à l'extérieur de l'Empire Romain », a pu dire Philipp Wilhelm von Hörnigk ${ }^{254}$. Les ins-

247 Whaley, « Die Habsburgermonarchie und das Heilige Römische Reich », pp. 288-318.

248 Mémoire de Colloredo (1746), cité par Stollberg-Rilinger, Maria Theresia, pp. 161-162.

249 Whaley, « Die Habsburgermonarchie und das Heilige Römische Reich », pp. 300-301, p. 300.

250 Beales, Joseph II, vol. 1, pp. 119-123; Whaley, « Die Habsburgermonarchie und das Heilige Römische Reich », p. 291, pp. 300-301; Stollberg-Rilinger, Des Kaisers alte Kleider, pp. 286-287.

251 Whaley, « Die Habsburgermonarchie und das Heilige Römische Reich », p. 301. Toutefois, selon Barbara Stollberg-Rilinger, le fait que François $\mathrm{I}^{\mathrm{er}}$ puis Joseph II aient commandé un rapport d'évaluation de l'utilité de la couronne impériale pour la Maison des Habsbourg témoigne assez de sa perte d'importance, même si les réponses apportées à cette enquête se révèlent très positives ; voir Stollberg-Rilinger, Das Heilige Römische Reich, p. 100.

252 Kugler, Die Reichskrone, pp. 122-124; Zedinger, Franz Stephan von Lothringen, p. 214.

253 Burkhardt, Vollendung und Neuorientierung, p. 440; Gnant, «Franz Stephan von Lothringen als Kaiser », p. 128.

254 Hörnigk, Oesterreich uber alles, p. 2 : « Durch vorangesetztes mein Oesterreich verstehe ich nicht bloser Dingen das Welt belobte, zu beyden Seiten des Donaustroms erstreckte Erzherzogthum dieses Namens; sondern an bey alle und jede des Teutschen Oesterreichischen Erzhauses, es sey in- oder außerhalb des Röm. Reichs gelegene Erb-Königreich und Länder, demnach Ungarn mit darunter begriffen ». Sur ce passage, voir Andruchowitz, « Philipp Wil- 
titutions impériales se détachent peu à peu de celles de la Monarchie. Dès 1620, la chancellerie d'Autriche prend ses distances avec la chancellerie d'Empire ${ }^{255}$. Toutefois cette dignité impériale semble indispensable. Elle offre en effet une forme d'unité. " „La nation allemande“, écho de l'Imperium Teutonicorum de Frédéric Barberousse, élément fédérateur du Saint Empire, semble ainsi s'effacer progressivement au profit d'un nouvel espace impérial, multinational, l'Empire des Habsbourg ", pour reprendre les termes d'Eric Hassler ${ }^{256}$. Quels insignes vont permettre de définir ce nouvel empire?

\section{b. L'insigne impérial familial dans les portraits}

En plus des Reichskleinodien officiels (ou insignes impériaux), de plus en plus d'insignes privés sont créés au cours de l'histoire du Saint Empire, en particulier par et pour les Habsbourg. Les objets impériaux conservés à Nuremberg ne sont en effet prêtés que pour le couronnement de l'empereur. La couronne impériale de Nuremberg ne leur appartenant pas, les Habsbourg ont besoin de leur propre couronne. Les régents font ainsi exécuter des ornements privés pour d'autres festivités. L'objet le plus connu, toujours conservé, est sans aucun doute la Rudolfskrone, la couronne privée de Rodolphe II. Selon les comptes-rendus de l'époque, il existait plusieurs Hauskronen ou couronnes impériales familiales. Si la couronne de Rodolphe est toujours à notre disposition aujourd'hui, les autres couronnes de la Maison ont été brisées, vendues ou fondues ${ }^{257}$.

Il nous reste donc la couronne privée de l'empereur Rodolphe II, confectionnée par le joaillier Jan Vermeyen en 1602, constituée d'un bracelet serti de lys, symbole de la dignité impériale, d'une mitre qui signale la position divine conférée à l'empereur, et d'un bracelet serti de huit gros diamants, allusion à la couronne impériale. Sur cette couronne, Rodolphe II s'est fait représenter dans ses quatre dignités : comme chef de guerre et vainqueur des Turcs, lors de son couronnement à Ratisbonne, en tant qu'empereur Romain, lors de sa chevau-

helm von Hörnigk », pp. 703-704; Heiss, « Ökonomie und Österreichbewußtsein », p. 230; Klingenstein, « Was bedeuten ‘Österreich' und ‘österreichisch' », pp. 200-201.

255 Hassler, «Construction, fractionnement et recomposition », p. 148 ; Hochedlinger, « Die Reichshofkanzlei », p. 326.

256 Hassler, «Construction, fractionnement et recomposition », p. 152.

257 Concernant ces couronnes, celle de l'empire et celle de Rodolphe, et pour savoir lesquelles furent portées par l'époux et le fils de Marie-Thérèse, voir notamment Kugler, Die Reichskrone, p. 124 ; Vocelka, Heller, Die Lebenswelt der Habsburger, pp. 175-177 ; voir aussi Matsche, Die K unst im Dienst der Staatsidee, vol. 1, p. 90. 
chée sur la colline du couronnement à Presbourg, comme roi de Hongrie, et enfin lors de son arrivée sur le Hradschin (Hradčany) à Prague, comme roi de Bohême ${ }^{258}$. Cette couronne de Rodolphe n'est pas forcément celle qui est représentée comme Hauskrone dans les portraits de Marie-Thérèse.

L'Empire conserve les anciens insignes depuis l'empereur Sigismund tandis que la Maison des Habsbourg se dote de nouveaux symboles ${ }^{259}$. La couronne de Rodolphe a, comme nous l'avons vu, une plus grande importance pour les Habsbourg car elle a été créée en tant que couronne privée et fait partie des insignes, qui d'un point de vue juridique, ne sont pas des insignes de l'Empire. La couronne de la Maison ne représente pas seulement la double dignité royale du monarque, elle peut aussi, au choix, remplacer l'une ou l'autre couronne qui symbolise l'un ou l'autre royaume ${ }^{260}$.

Dans l'inventaire de la Schatzkammer impériale, la couronne de Rodolphe II est recensée en 1677 comme Kayserliche Hauss-Cron, comme couronne impériale de la Maison ${ }^{261}$. Le lien de l'empire avec la Maison des Habsbourg est représenté par cet insigne qui est compris dans un sens universel ${ }^{262}$. L'empereur Léopold n'a besoin que de cette couronne, qui lui appartient personnellement ainsi qu'à sa famille, pour symboliser la souveraineté universelle liée à la Maison d'Autriche ${ }^{263}$.

De nombreux portraits du corpus représentent la couronne impériale familiale, seule ou avec les autres couronnes. Après 1745 , cet insigne figure très souvent au premier plan à côté de la couronne de Saint Étienne, rappelant ainsi les prétentions impériales de la Maison d'Autriche et de Marie-Thérèse elle-même. Ce type de portrait souligne leur volonté de créer un empire qui leur appartienne en propre, fondé à partir de leurs pays. La dignité impériale de la Maison d'Autriche, toujours d'actualité, apparaît toutefois dans un contexte nouveau, portée par une nouvelle famille, celle des Habsbourg-Lorraine et par une femme, Marie-Thérèse, épouse et mère, fondatrice de cette dynastie, aux côtés du nouvel empereur issu de la maison de Lorraine.

258 Haag, Kaiserliche Schatzkammer, pp. 136-139. Cette couronne deviendra celle de l'Empire d'Autriche. Voir aussi Polleross, « Kaiser, König, Landesfürst », pp. 196-197.

259 Matsche, " Die Verherrlichung der kaiserlichen Majestät », p. 384. Voir cet ouvrage, concernant la transmission de la dignité impériale sous Charles VI; Matsche, Die Kunst im Dienst der Staatsidee, vol. 1, p. 90.

260 Schwarzenberg, Die Sankt Wenzels-Krone, p. 26; Pons, Wo der gekrönte Löw hat seinen Kayser-Sitz, p. 235.

261 Vocelka, Heller, Die Lebenswelt der Habsburger, p. 175. Pons, Wo der gekrönte Löw hat seinen Kayser-Sitz, p. 235.

262 Pons, Wo der gekrönte Löw hat seinen Kayser-Sitz, pp. 234-239, notamment p. 235.

263 Pons, Wo der gekrönte Löw hat seinen Kayser-Sitz, p. 235. 
Plus de la moitié des portraits du corpus exposent soit la couronne impériale familiale, soit la couronne de Hongrie, au premier plan, devant ou proche des autres couronnes. Ce sont les deux modèles essentiels de la représentation. Cette couronne impériale familiale apparaît notamment dans les portraits réalisés lors du couronnement de François Étienne comme empereur en 1745 ainsi que lors du veuvage de Marie-Thérèse après 1765, à l'époque de la corégence avec son fils Joseph II. Tous les pays de la Monarchie possèdent de tels portraits.

Le modèle de Marie-Thérèse en robe de soie bleue avec la couronne impériale familiale (ou couronne impériale héraldique, ou encore Mitrakrone) peinte devant les autres couronnes des pays est particulièrement fréquent. Ce nouveau type de portrait se retrouve chez les Seckendorff (P 89) en Allemagne, aux châteaux d'Opočno (P 97) et de Veltrusy en Bohême (P 114), auprès de partisans du régime comme les Colloredo ou les Chotek, auprès d'ecclésiastiques comme aux abbayes de Göttweig (P 96), Pannonhalma (P 86) ou Teplá (P 94). Il est souvent accompagné d'un portrait de François Étienne pour compléter la représentation du couple impérial, l'empereur avec la couronne impériale et la souveraine des pays héréditaires. C'est le cas chez des princes ecclésiastiques de l'Empire, comme dans le Fronhof à Augsbourg (P 105) et au château des princes-évêques de Spire à Bruchsal (P 88, Figure 21). Ce type de portraits montrant la souveraine vêtue d'une robe de couleur bleue, couleur de la Vierge Marie, symbole par excellence de la pureté et de la souveraineté, est abondamment distribué. C'est le motif de légitimation d'une certaine période, celle du couronnement de François Étienne, qui devient alors François $\mathrm{I}^{\mathrm{er}}$, où Marie-Thérèse doit assumer son rôle d'épouse de l'empereur et de " souverain » des territoires héréditaires. Après l'intermède bavarois, une subtile diplomatie de représentation et de reconquête est mise en place par la dynastie, en particulier par François Étienne, qui est retranscrite dans les portraits du couple impérial.

Remarquons que François Étienne de Lorraine ne porte pas la couronne impériale de Nuremberg lorsqu'il entre le 4 octobre 1745 dans l'église Saint-Bartholomé à Francfort ${ }^{264}$. Il porte alors une couronne privée. Sur cette couronne, on peut voir les armes de la Maison ${ }^{265}$, c'est cette couronne même, ou une couronne de famille très similaire, que l'on retrouve dès 1745 représentée souvent en premier plan devant les autres couronnes sur les portraits de Marie-Thérèse.

Par la suite, à l'occasion du couronnement de Joseph II comme roi des Romains en 1764, la couronne impériale familiale, la Rudolfskrone, est également

264 Vocelka, Heller, Die Lebenswelt der Habsburger, p. 176; Zedinger, Franz Stephan von Lothringen, p. 195.

265 Kugler, Die Reichskrone, pp. 122-124. 
portée comme Hauskrone par l'empereur François $\mathrm{I}^{\mathrm{er}}$. Sur les tableaux de l'atelier de Meytens, on peut très distinctement reconnaître le père avec la couronne de Rodolphe ${ }^{266}$. Marie-Thérèse n'est pas présente au couronnement de son fils et selon le point de vue de l'héritier lui-même, Joseph, la cérémonie est « désagréable et inutile ${ }^{267}$. Malgré ce mépris affiché pour la dignité impériale, la représentation de Marie-Thérèse et de sa famille n'en continue pas moins d'exhiber les insignes impériaux en particulier lors de l'élection de François Étienne en 1745 et lors de celle de Joseph, en 1764, comme roi des Romains ${ }^{268}$.

Marie-Thérèse refuse de se laisser couronner en tant qu'épouse de l'empereur en 1745. Pour autant, la dignité impériale n'est pas vraiment interrompue par la montée sur le trône d'une femme et par la fondation d'une nouvelle dynastie. Au contraire, le fils de Marie-Thérèse, premier empereur de la dynastie des Habsbourg-Lorraine, est montré comme l'héritier du Saint Empire, le futur roi des Romains et empereur du Saint Empire romain germanique: c'est une revendication. La dignité impériale conserve toujours un intérêt stratégique pour les Habsbourg-Lorraine.

Conformément à la situation juridique de Marie-Thérèse, très peu de portraits la peignent avec la couronne impériale de Nuremberg. Marie-Thérèse demeure à la fois fille, femme et mère d'empereurs du Saint Empire romain germanique. Lorsque l'insigne apparaît dans les portraits de Marie-Thérèse, la couronne impériale de Nuremberg est liée à la Bohême et aux HabsbourgLorraine, ou au rôle de Marie-Thérèse comme femme de l'empereur.

Dans la plupart des cas, les portraits du couple impérial montrent François Étienne avec la couronne impériale de Nuremberg, puis après la mort de ce dernier, son fils Joseph est peint à côté de celle-ci. Marie-Thérèse apparaît en pendant comme souveraine légitimée et couronnée, régnant sur ses territoires héréditaires. Charles VI utilise déjà souvent toutes les couronnes de ses domaines de souveraineté comme insignes de son pouvoir dans ses portraits ${ }^{269}$. Au

266 Macek, Die Krönung Josephs II., pp. 68-71, 77-78. À l'occasion du couronnement de Joseph comme roi des Romains, François Étienne porte la couronne de Rodolphe, p. 71. Sur le couronnement de Joseph II, voir aussi Bauer, " Eine Stadt im Ausnahmezustand »; StollbergRilinger, Des Kaisers alte Kleider, pp. 229-246.

267 Cité d'après Stollberg-Rilinger, Des Kaisers alte Kleider, p. 237.

268 Voir notamment sur ce point les propos qu'en tient Braun ; Braun, "Maria Theresia ", pp. 218-219.

269 Le portrait de Charles VI vers 1730 attribué à Auerbach et aujourd'hui à la Schatzkammer du Kunsthistorisches Museum de Vienne, GG Inv.-Nr. 2140, en est un bon exemple ; voir Hauenfels, Visualisierung von Herrschaftsanspruch, pp. 247-248. Voir aussi un portrait de Charles VI avec plusieurs couronnes réalisé par Johann Gottfried Auerbach, Inv. Nr. 3464, 
moins depuis la Pragmatique Sanction de 1713, il est lui-même représenté régulièrement de cette manière, comme l'atteste un certain nombre de portraits exécutés par le peintre Johann Gottfried Auerbach dans les années 1730, à l'exemple de celui qui se trouve aujourd'hui au Kunsthistorisches Museum de Vienne, dans la Schatzkammer ${ }^{270}$. Le père de Marie-Thérèse est peint en habit de l'Ordre de la Toison d'Or, assis, les couronnes sont à ses côtés sur une table. La couronne impériale de Nuremberg devance celles de Hongrie et de Bohême, soulignant ainsi les principaux titres de Charles VI. La représentation de sa fille Marie-Thérèse lui ressemble sur ce point, dans la juxtaposition des couronnes.

\section{Conclusion}

La représentation princière aux côtés des différentes couronnes ne débute pas avec Marie-Thérèse mais existe déjà sous son père Charles VI. Marie-Thérèse hérite d'un passé et d'une tradition de représentation familiale qu'elle remanie à sa façon.

Les insignes et symboles de la Monarchie et des pays, comme le chapeau archiducal, les couronnes de Hongrie et de Bohême, la Hauskrone (couronne de Rodolphe II ou couronne impériale familiale), sont montrés dans les portraits de Marie-Thérèse. Selon les périodes, certaines couronnes sont mises en avant. Dans tous les cas, les insignes sont représentés, ensemble, à côté de la souveraine, pour témoigner de la souveraineté des Habsbourg sur les territoires. Nous avons consacré ce chapitre aux liens entre les évènements, les régions de la Monarchie et les types de portraits de Marie-Thérèse.

La couronne hongroise est la plus et la mieux représentée, c'est en effet la plus haute dignité possédée par Marie-Thérèse. Le royaume de Hongrie ne fait pas partie du Saint Empire, ce qui éloigne la représentation de Marie-Thérèse de l'idée d'imperium, Empire germanique, mais la rapproche de l'idée d'imperium autrichien. L'impossibilité pour Marie-Thérèse d'être élue à la tête du Saint Empire devient moins grave si la légitimité de la nouvelle Monarchie est davantage liée à la couronne de Saint Étienne ou encore à la couronne impériale familiale, et non plus principalement à la couronne impériale de Nuremberg.

Représenter au côté de Marie-Thérèse la couronne familiale mais aussi celle de Hongrie, qui ne fait pas partie du Saint Empire, peut être interprété comme

Kunsthistorisches Museum, Vienne, Pippal, Cat. N. 18, "Portrait de l'empereur Charles VI », pp. 84-85 ; Pons, Wo der gekrönte Löw hat seinen Kayser-Sitz, p. 235 et pp. 372-376.

270 Hauenfels, Visualisierung von Herrschaftsanspruch, pp. 247-248. 
une manière de faire oublier la perte provisoire de la couronne impériale entre 1742 et 1745 . La valeur symbolique de la Sainte Couronne de Hongrie explique aussi toutes les mesures entreprises par Marie-Thérèse pour la rehausser. En raison de la séparation croissante entre la souveraineté sur les États héréditaires et le rôle réel de l'empereur du Saint Empire, le royaume de Hongrie offre une autre dignité indispensable pour la légitimité de Marie-Thérèse, du moins est-ce une hypothèse de notre part.

La couronne impériale de Nuremberg n'est pas totalement absente mais elle est surtout montrée à côté de François Étienne comme il se doit. Dans les propres portraits de la souveraine, la couronne impériale peut être représentée à côté de la couronne de Bohême ou à proximité de Joseph enfant. Symbole d'unité familiale, la couronne impériale familiale ou la Hauskrone est très souvent peinte à côté de Marie-Thérèse et des autres couronnes.

D’autres insignes comme les vêtements peuvent jouer un rôle identitaire important et marquer la souveraineté sur certains territoires en rendant hommage aux pays respectifs. C'est lors des cérémonies d'hommage et lors des couronnements en 1740, 1741, 1743 et 1745, ou à l'occasion de la reprise de pouvoir dans certaines provinces, que la plupart des types de portraits apparaissent et sont ensuite reproduits tout au long du règne.

Si les types de portraits sont réalisés en fonction de certaines périodes et de publics bien précis, des portraits comme le modèle à côté de la couronne de Hongrie ou celui proche de la couronne impériale familiale, symbole propre à la Maison d'Autriche, sont unanimement répandus entre 1745 et la mort de la souveraine en 1780 .

Marie-Thérèse parle de Sa Maison, Mein Haus, ou encore de Notre Maison, Unser Haus, lorsqu'elle écrit et évoque sa Maison. Ce terme renvoie alors à une désignation politique et dynastique ${ }^{271}$. Et en tant que telle, c'est la forme relativement simplifiée d'un ensemble composé de différentes parties, à cet égard assez semblable au Saint Empire. Mein Haus semble dans le cas de MarieThérèse se référer avant tout à la famille nombreuse de l'impératrice, celle des Habsbourg-Lorraine, qui englobe, pour reprendre la métaphore corporative du corps humain, d'autres maisons, d'autres membres et d'autres royaumes.

Après avoir analysé le contenu des portraits sous l'angle des évènements et des régions, nous les aborderons dans le prochain chapitre sous l'angle du genre. Le rôle féminin de Marie-Thérèse dans ses tableaux est en effet très contxrasté.

271 Klingenstein, « Was bedeuten ‘Österreich' und ‘österreichisch’? » p. 171. Kallbrunner, Maria Theresias Politische Testamente. 